

\title{
The effect of measurement errors on the performance of the homogenously weighted moving average $\mathrm{X}^{-}$ monitoring scheme with estimated parameters
}

Maonatlala Thanwane, Jean-Claude Malela-Majika, Philippe Castagliola, Sandile Charles Shongwe

\section{To cite this version:}

Maonatlala Thanwane, Jean-Claude Malela-Majika, Philippe Castagliola, Sandile Charles Shongwe. The effect of measurement errors on the performance of the homogenously weighted moving average $\mathrm{X}$ - monitoring scheme with estimated parameters. Journal of Statistical Computation and Simulation, 2021, 91 (7), pp.1306-1330. 10.1080/00949655.2020.1850728 . hal-03212037

\section{HAL Id: hal-03212037 \\ https://hal.science/hal-03212037}

Submitted on 2 Sep 2021

HAL is a multi-disciplinary open access archive for the deposit and dissemination of scientific research documents, whether they are published or not. The documents may come from teaching and research institutions in France or abroad, or from public or private research centers.
L'archive ouverte pluridisciplinaire HAL, est destinée au dépôt et à la diffusion de documents scientifiques de niveau recherche, publiés ou non, émanant des établissements d'enseignement et de recherche français ou étrangers, des laboratoires publics ou privés. 
The effect of measurement errors on the performance of the homogenously weighted moving average $\bar{X}$ monitoring scheme with estimated parameters

\author{
Maonatlala Thanwane ${ }^{1}$ \\ Email: maonatlalaT@statssa.gov.za \\ Jean-Claude Malela-Majika ${ }^{1 *}$ \\ Email: malelm@unisa.ac.za \\ Philippe Castagliola ${ }^{2}$ \\ Email: philippe.castagliola@univ-nantes.fr
}

Sandile Charles Shongwe ${ }^{1}$

Email: sandile@tuks.co.za

${ }^{1}$ Department of Statistics, College of Science, Engineering and Technology, University of South Africa, P O Box 392 UNISA 0003, Pretoria, South Africa.

${ }^{2}$ Département Qualité Logistique Industrielle et Organisation, Université de Nantes \& LS2N UMR CNRS 6004, Nantes, France.

\footnotetext{
${ }^{*}$ Corresponding author. E-mail: malelm@unisa.ac.za
} 


\title{
The effect of measurement errors on the performance of the homogenously weighted moving average $\bar{X}$ monitoring scheme with estimated parameters
}

\begin{abstract}
Classical monitoring schemes are typically designed under the assumption of known process parameters, perfect measurements and normality. In real-life applications, these assumptions are often violated. Thus, their Phase II performances are negatively affected by both measurement errors and parameter estimation. In this paper, the performance of the homogenously weighted moving average (HWMA) scheme is investigated under the assumption of unknown process parameters with and without measurement errors using the characteristics of the run-length distribution through intensive simulations. The negative effect of measurement errors is reduced using multiple measurements sampling strategy. The effects of the Phase I sample size on the Phase II performance as well as the robustness to non-normality of the HWMA scheme are also investigated. Moreover, it is found that the negative effect of the measurement errors is higher as the smoothing parameter increases and the larger the Phase I sample size, the smaller the effect of measurement errors. Moreover, the Phase II performance of the HWMA $\bar{X}$ scheme is compared with the corresponding memory-type monitoring schemes under the effect of both parameter estimation and measurement errors. An illustrative example is given to demonstrate the implementation in real-life applications.
\end{abstract}

Keywords: Homogenously Weighted Moving Average scheme; Linear covariate error model; Linearly increasing variance; Measurement error; Multiple measurements; Parameter estimation.

\section{Introduction}

Any efficient monitoring scheme needs to be able to distinguish between two sources of variation, i.e. the common (or chance) causes and the assignable (or special) causes of variation. When the process runs in the presence of common causes only, the process is considered to be in-control (IC); otherwise, the process is said to be out-of-control (OOC). In statistical process monitoring (SPM), when practitioners are interested in monitoring smallto-moderate shifts in the process parameters, popular memory-type monitoring schemes such as the cumulative sum (CUSUM) or the exponentially weighted moving average (EWMA) can be used, see for instance the SPM books by [1-3]. While the majority of the SPM literature and the latter books discuss monitoring schemes based on simple random sampling (SRS), there are other memory-type schemes based on structured sampling strategies, like the ranked set sampling (RSS); see for instance [4-5]. Another memory-type scheme that is gaining some interest among SPM researchers is the generally weighted moving average (GWMA) schemes which is essentially an EWMA scheme with an additional adjustment design parameter (i.e. the GWMA scheme is slightly more complex than the EWMA scheme); see the review paper by [6]. However, [6] noted that, although the GWMA scheme 
has a better performance than the EWMA scheme, its statistical design is more complicated than that of the EWMA scheme.

More recently, Abbas [7] developed a new memory-type scheme called the homogeneously weighted moving average (HWMA) monitoring scheme. The HWMA scheme is an improvement of the EWMA scheme in terms of the statistical design simplicity and OOC performance. That is, the recent and past observations used to compute the charting statistics of the EWMA scheme have a geometrically decreasing weight structure from the most recent observation to the previous ones. However, the HWMA scheme allocates a specific weight to the current observation and equal weights for all previous observations. In essence, the charting statistics of the HWMA control chart overcome the problem of varying weights in a geometrically decreasing manner that is associated with the EWMA chart (and by extension, the GWMA scheme).

So far in the SPM literature, there are ten publications discussing the HWMA-type monitoring schemes, see [7-16]. That is, Abbas [7] proposed a new HWMA $\bar{X}$ scheme to monitor the process mean and derived its run-length properties. Next, [8] developed the HWMA $\bar{X}$ scheme that uses auxiliary information variable in the form of a regression estimator. Thereafter, [9] discussed the HWMA $\bar{X}$ scheme that uses structured sampling methods based on RSS. The double (and hybrid) HWMA $\bar{X}$ schemes which involve the use of two smoothing parameters were introduced by [10] and [11], respectively. Next, [12] proposed the mixed HWMA-CUSUM scheme where the HWMA statistic is used as an input of the CUSUM scheme. Dawod et al. [13] proposed the HWMA scheme to monitor linear profiles using a Bayesian estimation approach. A multivariate HWMA scheme for monitoring the process mean vector when parameters are either known or unknown are discussed in [14] and [15], respectively. Finally, [16] proposed two nonparametric HWMA schemes based on the sign and Wilcoxon signed-rank statistics for monitoring location parameters in the case of skewed and symmetric distributions, respectively.

The majority of the monitoring schemes are typically based on the assumption of known process parameters (henceforth denoted as Case K). However, in many real-life applications, the process parameters are unknown (henceforth denoted as Case U). The Case U scenario requires monitoring schemes to be applied in a two-phase approach, i.e. Phase I and Phase II; see for instance [17-19]. In Phase I, monitoring schemes are implemented retrospectively in order to estimate the distribution parameters using an IC reference sample. However, in Phase II, monitoring schemes are implemented prospectively to continuously monitor any 
departures from an IC state using the parameters estimated in Phase I. It is well-known that parameter estimation significantly degrades the sensitivity of a monitoring scheme. Therefore, it is very important to investigate the performance of the existing and new monitoring schemes under the assumption of unknown process parameters. Other recent contributions to parameter estimation effect can be found in the review paper by [20].

All the above mentioned HWMA $\bar{X}$ schemes assume that measurements on observations are exact and thus, only a single measurement on each observation is taken. However, exact measurements almost do not exist in real-life applications, because as stated in the review paper by [21]: “... wherever there is a human involvement, an exact measurement is a rare phenomenon in any manufacturing and service environment; hence a difference between the real quantities and the measured ones will always exist even with highly sophisticated advanced measuring instruments". Therefore, in this paper, the performance of the HWMA $\bar{X}$ scheme is investigated under the Case $\mathrm{U}$ assumption, with and without measurement errors, when the underlying observations follow normal or non-normal distributions. The covariate error model with a constant and a linearly increasing variance are both used to model the measurement errors. In the review paper by [21], it is stated that the most used remedial approach to counteract measurement errors is the multiple measurements approach proposed by [22]; hence, in this paper, this strategy is also implemented. Multiple measurements approach involves taking at least two measurements (i.e. $r \geq 2$ ) for each sampled unit, which effectively reduces the effect of the measurement errors. For other recent works on measurement errors in the SPM context, see [23-31].

The rest of this paper is organised as follows: In Section 2, the main properties of the HWMA $\bar{X}$ scheme without measurement errors under the Cases $\mathrm{K}$ and $\mathrm{U}$ scenarios are provided. Section 3 introduces the HWMA $\bar{X}$ scheme in Case U with measurement errors. The OOC performance of the HWMA scheme and the robustness to non-normality are studied in Section 4. Moreover, the OOC performance of the HWMA scheme is compared to those of the CUSUM, EWMA and GWMA schemes. An illustrative example based on a real-life application is given in Section 5 and some concluding remarks are presented in Section 6.

\section{Design of the HWMA $\bar{X}$ scheme}

\subsection{Parameters known (Case K)}

Let $X_{t i}\{t=1,2, \ldots$, and $i=1,2, \ldots, n\}$ be a set of samples of independent normal random variables, i.e. $X_{t i} \sim N\left(\mu_{0}+\delta \sigma_{0}, \sigma_{0}\right)$, where $\mu_{0}$ is the IC mean value, $\sigma_{0}$ is the IC standard 
deviation and $\delta$ is the magnitude of the shift in standard deviation units. When $\delta=0$, the process is considered to be IC, which implies $X_{t i} \sim N\left(\mu_{0}, \sigma_{0}\right)$. However, when $\delta \neq 0$ the process is OOC. Let $\bar{X}_{t}\left(=\sum_{i=1}^{n} X_{t i} / n\right)$ be the sample mean of the $t^{t h}$ subgroup. The plotting statistic of the HWMA $\bar{X}$ scheme (denoted as $H_{t}$ ) is defined by

$$
H_{t}=\lambda \bar{X}_{t}+(1-\lambda) \overline{\bar{X}}_{t-1} \text {, }
$$

with

$$
\overline{\bar{X}}_{t-1}=\frac{\sum_{v=1}^{t-1} \bar{X}_{v}}{t-1}
$$

where $\lambda(0<\lambda \leq 1)$ is the smoothing constant and $\overline{\bar{X}}_{t-1}$ is the mean of the previous $t-1$ subgroup sample means. The initial value of $\overline{\bar{X}}_{t-1}$ (i.e. $\overline{\bar{X}}_{0}$ ) is typically set to be equal to the target mean $\mu_{0}$. Abbas [7] showed that (1) can also be written as

$$
H_{t}=\lambda \bar{X}_{t}+\left(\left(\frac{1-\lambda}{t-1}\right) \bar{X}_{t-1}+\left(\frac{1-\lambda}{t-1}\right) \bar{X}_{t-2}+\cdots+\left(\frac{1-\lambda}{t-1}\right) \bar{X}_{2}+\left(\frac{1-\lambda}{t-1}\right) \bar{X}_{1}\right) .
$$

From (2), it can be seen that the HWMA $\bar{X}$ statistic assigns weight $\lambda$ to the current sample and a weight $(1-\lambda)$ is homogeneously (or equally) distributed to the previous $t-1$ samples. Abbas [7] showed that the mean and variance of the plotting statistic in (1) or (2) are given by

$$
E\left(H_{t}\right)=\mu_{0}
$$

and

$$
\operatorname{Var}\left(H_{t}\right)=\sigma_{H_{t}}^{2}= \begin{cases}\frac{\lambda^{2} \sigma_{0}^{2}}{n}, & t=1 \\ \frac{\lambda^{2} \sigma_{0}^{2}}{n}+\frac{(1-\lambda)^{2} \sigma_{0}^{2}}{n(t-1)}, & t>1\end{cases}
$$

respectively. Therefore, the time-varying lower and upper control limits (i.e. $L C L_{t}$ and $U C L_{t}$ ) of the HWMA $\bar{X}$ monitoring scheme are defined by

$$
L C L_{t}= \begin{cases}\mu_{0}-L \sqrt{\frac{\lambda^{2} \sigma_{0}^{2}}{n},} & t=1 \\ \mu_{0}-L \sqrt{\frac{\lambda^{2} \sigma_{0}^{2}}{n}+\frac{(1-\lambda)^{2} \sigma_{0}^{2}}{n(t-1)}}, & t>1\end{cases}
$$

and 


$$
U C L_{t}= \begin{cases}\mu_{0}+L \sqrt{\frac{\lambda^{2} \sigma_{0}^{2}}{n},} & t=1 \\ \mu_{0}+L \sqrt{\frac{\lambda^{2} \sigma_{0}^{2}}{n}+\frac{(1-\lambda)^{2} \sigma_{0}^{2}}{n(t-1)}}, & t>1\end{cases}
$$

respectively; where $L$ is the control limits constant that is set to have an IC $A R L$ approximately equal to some pre-specified nominal IC $A R L$ (i.e. $A R L_{0}$ ). Thus, the HWMA $\bar{X}$ scheme gives a signal if the plotting statistic in (1) plots beyond the control limits defined in (4); that is, if $H_{t} \geq U C L_{t}$ or $H_{t} \leq L C L_{t}$. In case the process has been running for a long time (i.e. $t \rightarrow \infty$ ), the term $\frac{(1-\lambda)^{2} \sigma_{0}^{2}}{n(t-1)} \rightarrow 0$. Therefore, the control limits in (4) reduce to the following asymptotic ones

$$
U C L / L C L=\mu_{0} \pm L \sqrt{\frac{\lambda^{2} \sigma_{0}^{2}}{n}},
$$

and, in this case, the process is OOC if $H_{t} \geq U C L$ or $H_{t} \leq L C L$.

\subsection{Parameters unknown (Case U)}

Since it is well-known that the estimation of the process parameters significantly degrades the performance of any monitoring scheme (see [17-20]), the investigation of the effect of parameter estimation on the performance of the HWMA $\bar{X}$ scheme is of great importance. In Case U, the process parameters are estimated in Phase I (using $m$ reference samples each of size $n$ ) when the process is deemed to be IC. The unbiased estimators for $\mu_{0}$ and $\sigma_{0}$ are defined by

$$
\hat{\mu}_{0}=\frac{\sum_{k=1}^{m} \sum_{i=1}^{n} Y_{k i}}{m n}
$$

and

$$
\hat{\sigma}_{0}=\frac{\sqrt{\frac{\sum_{k=1}^{m} \sum_{i=1}^{n}\left(Y_{k i}-\bar{Y}_{k}\right)^{2}}{m(n-1)}}}{c_{4, m}}
$$

respectively; where $\left\{Y_{k i}: k=1, \ldots, m\right.$ and $\left.i=1, \ldots, n\right\}$ is a sequence of IC Phase I observations, with $\bar{Y}_{k}\left(=\sum_{i=1}^{n} Y_{k i} / n\right)$ and $c_{4, m}=\frac{\sqrt{2} \Gamma\left(\frac{m(n-1)+1}{2}\right)}{\sqrt{m(n-1)} \Gamma\left(\frac{m(n-1)}{2}\right)}$ is an un-biasing constant, see [7].

Therefore, using Phase I estimates in (6), it follows that the time-varying control limits of the HWMA $\bar{X}$ scheme used to monitor the process mean in Phase II are given by 


$$
L C L_{t}= \begin{cases}\hat{\mu}_{0}-L \sqrt{\left(\frac{\lambda^{2} \hat{\sigma}_{0}^{2}}{n}\right)}, & t=1 \\ \hat{\mu}_{0}-L \sqrt{\frac{\lambda^{2} \hat{\sigma}_{0}^{2}}{n}+\frac{(1-\lambda)^{2} \hat{\sigma}_{0}^{2}}{n(t-1)}}, & t>1\end{cases}
$$

and

$$
U C L_{t}= \begin{cases}\hat{\mu}_{0}+L \sqrt{\frac{\lambda^{2} \hat{\sigma}_{0}^{2}}{n}}, & t=1 \\ \hat{\mu}_{0}+L \sqrt{\frac{\lambda^{2} \hat{\sigma}_{0}^{2}}{n}+\frac{(1-\lambda)^{2} \hat{\sigma}_{0}^{2}}{n(t-1)}}, & t>1 .\end{cases}
$$

However, the Phase II asymptotic control limits of the HWMA $\bar{X}$ scheme are given by

$$
U C L / L C L=\hat{\mu}_{0} \pm L \sqrt{\frac{\lambda^{2} \hat{\sigma}_{0}^{2}}{n}}
$$

\section{Design of the HWMA scheme in Case $U$ under the effect of measurement errors}

\subsection{Covariate error model with a constant variance}

Assume that the true value of the quality characteristic $X_{t, i}$ defined in Section 2 is only observed through a value $\left\{X_{t, i, j}^{*}: t=1,2, \ldots ; i=1,2, \ldots, n ; j=1, \ldots, r\right\}$ described by the expression $X_{t, i, j}^{*}=A+B X_{t, i}+\varepsilon_{t, i, j} \sim N\left(\mu_{0}, \sigma_{0}^{2}+\sigma_{M}^{2}\right)$, where $A$ and $B$ are two constants depending on the measurement system location error; see [22]. For the sake of simplicity, it is assumed that $A=0$ and $B=1$. Also, $r$ denotes the number of measurements taken in each sampled subgroup unit and $\varepsilon_{t, i, j} \sim N\left(0, \sigma_{M}^{2}\right)$ is a random error due to the measurement error that is distributed independently of $X_{t, i}$; where $\sigma_{M}^{2}$ is the variance of the measurement system. Assuming that $n$ observations from the sequence $X_{t, i, j}^{*}$ at each sampling point have been collected, the mean

$$
\bar{X}_{t}^{*}=\frac{1}{n r} \sum_{i=1}^{n} \sum_{j=1}^{r} X_{t, i, j}^{*}=\frac{1}{n} \sum_{i=1}^{n} X_{t, i}+\frac{1}{n r} \sum_{i=1}^{n} \sum_{j=1}^{r} \varepsilon_{t, i, j}
$$

needs to be calculated. Thus, the plotting statistic of the HWMA scheme in Case U with measurement errors (henceforth denoted by HWMA $\bar{X}^{*}$ scheme) is defined by

$$
H_{t}^{*}=\lambda \bar{X}_{t}^{*}+(1-\lambda) \overline{\bar{X}}_{t-1}^{*}
$$

where $\overline{\bar{X}}_{t-1}^{*}$ is the mean of the previous $t-1$ sample means and hence, (9) can be written as 


$$
H_{t}^{*}=\lambda \bar{X}_{t}^{*}+\left(\left(\frac{1-\lambda}{t-1}\right) \bar{X}_{t-1}^{*}+\left(\frac{1-\lambda}{t-1}\right) \bar{X}_{t-2}^{*}+\cdots+\left(\frac{1-\lambda}{t-1}\right) \bar{X}_{2}^{*}+\left(\frac{1-\lambda}{t-1}\right) \bar{X}_{1}^{*}\right)
$$

The initial value of $\overline{\bar{X}}_{t-1}^{*}$ (i.e. $\bar{X}_{0}^{*}$ ) is set to be equal to the estimated mean $\hat{\mu}_{0}$. Thus, the expected value and variance of the plotting statistic $H_{t}^{*}$ defined in (9) are

$$
E\left(H_{t}^{*}\right)=\hat{\mu}_{0}
$$

and

$$
\operatorname{Var}\left(H_{t}^{*}\right)=\sigma_{H_{t}^{*}}^{2}= \begin{cases}\lambda^{2} \frac{r \hat{\sigma}_{0}^{2}+\hat{\sigma}_{M}^{2}}{n r}, & \text { if } t=1 \\ \left(\lambda^{2}+\frac{(1-\lambda)^{2}}{t-1}\right)\left(\frac{r \hat{\sigma}_{0}^{2}+\hat{\sigma}_{M}^{2}}{n r}\right), & \text { if } t>1 .\end{cases}
$$

Let $\gamma=\frac{\sigma_{M}}{\widehat{\sigma}_{0}}$ represents the standardized ratio of the measurement system variability to the process variability; and then $\operatorname{Var}\left(H_{t}^{*}\right)$ in (10) reduces to

$$
\operatorname{Var}\left(H_{t}^{*}\right)=\sigma_{H_{t}^{*}}^{2}= \begin{cases}\frac{\lambda^{2} \hat{\sigma}_{0}^{2}}{n}\left(1+\frac{\gamma^{2}}{r}\right), & \text { if } t=1 \\ \left(\frac{\lambda^{2} \hat{\sigma}_{0}^{2}}{n}+\frac{(1-\lambda)^{2} \hat{\sigma}_{0}^{2}}{n(t-1)}\right)\left(1+\frac{\gamma^{2}}{r}\right), & \text { if } t>1 .\end{cases}
$$

The value of $r$ is equal to 1 when a standard single measurement is used per sampling unit. However, as $r$ increases, the negative effect of the variance of the measurement error component is reduced; that is, as $r \rightarrow \infty$, then $\frac{\gamma^{2}}{r} \rightarrow 0$. An optimal balance has to be found between $\gamma$ and the resources to realise a reasonable outcome - this point is addressed in Section 4.2 .

When $\bar{X}_{t}$ is from a perfect measurement system, then $\sigma_{M}=0$, so that $\gamma=0$; otherwise, $\gamma>$ 0 . The time-varying control limits of the HWMA $\bar{X}^{*}$ scheme with $r$-measurements are defined by:

$$
L C L_{t}= \begin{cases}\hat{\mu}_{0}-L^{*} \sqrt{\frac{\lambda^{2} \hat{\sigma}_{0}^{2}}{n}\left(1+\frac{\gamma^{2}}{r}\right)}, & t=1 \\ \hat{\mu}_{0}-L^{*} \sqrt{\left(\frac{\lambda^{2} \hat{\sigma}_{0}^{2}}{n}+\frac{(1-\lambda)^{2} \hat{\sigma}_{0}^{2}}{n(t-1)}\right)\left(1+\frac{\gamma^{2}}{r}\right)}, & t>1\end{cases}
$$

and 


$$
U C L_{t}= \begin{cases}\hat{\mu}_{0}+L^{*} \sqrt{\frac{\lambda^{2} \hat{\sigma}_{0}^{2}}{n}\left(1+\frac{\gamma^{2}}{r}\right)}, & t=1 \\ \hat{\mu}_{0}+L^{*} \sqrt{\left(\frac{\lambda^{2} \hat{\sigma}_{0}^{2}}{n}+\frac{(1-\lambda)^{2} \hat{\sigma}_{0}^{2}}{n(t-1)}\right)\left(1+\frac{\gamma^{2}}{r}\right)}, & t>1\end{cases}
$$

where $L^{*}$ is control limit width parameter of the HWMA $\bar{X}^{*}$ scheme with $r$-measurements.

Since the term $\frac{(1-\lambda)^{2} \widehat{\sigma}_{0}^{2}}{n(t-1)} \rightarrow 0$ when the process has been running for a while, the asymptotic control limits of the HWMA $\bar{X}^{*}$ scheme with $r$-measurements are defined by

$$
U C L / L C L=\hat{\mu}_{0} \pm L^{*} \sqrt{\frac{\lambda^{2} \hat{\sigma}_{0}^{2}}{n}\left(1+\frac{\gamma^{2}}{r}\right)} .
$$

\subsection{Covariate error model with a linearly increasing variance}

In some situations, the measurement error $\sigma_{M}$ should no longer be considered as being a constant but it should be considered as an increasing function of the mean of the variable $X_{t, i}$, i.e. $\sigma_{M}^{2}=C+D \hat{\mu}_{0}$, where $C$ and $D$ are constants; and thus, $X_{t, i, j}^{*} \sim N\left(A+B \hat{\mu}_{0}, B^{2} \hat{\sigma}_{0}^{2}+C+\right.$ $D \hat{\mu}_{0}$ ). One more time, for simplicity, assume $A=0$ and $B=1$, then the Phase II time-varying control limits of the HWMA $\bar{X}^{*}$ scheme with $r$-measurements and linearly increasing variance are defined by:

$$
L C L_{t}= \begin{cases}\hat{\mu}_{0}-L^{*} \sqrt{\lambda^{2}\left(\frac{\hat{\sigma}_{0}^{2}}{n}+\frac{C+D \hat{\mu}_{0}}{n r}\right)}, & t=1 \\ \hat{\mu}_{0}-L^{*} \sqrt{\left(\lambda^{2}+\frac{(1-\lambda)^{2}}{t-1}\right)\left(\frac{\hat{\sigma}_{0}^{2}}{n}+\frac{C+D \hat{\mu}_{0}}{n r}\right)}, & t>1\end{cases}
$$

and

$$
U C L_{t}= \begin{cases}\hat{\mu}_{0}+L^{*} \sqrt{\lambda^{2}\left(\frac{\hat{\sigma}_{0}^{2}}{n}+\frac{C+D \hat{\mu}_{0}}{n r}\right)}, & t=1 \\ \hat{\mu}_{0}+L^{*} \sqrt{\left(\lambda^{2}+\frac{(1-\lambda)^{2}}{t-1}\right)\left(\frac{\hat{\sigma}_{0}^{2}}{n}+\frac{C+D \hat{\mu}_{0}}{n r}\right)}, & t>1\end{cases}
$$

Similarly, as $r \rightarrow \infty$, then $\frac{C+D \widehat{\mu}_{0}}{n r} \rightarrow 0$, which means as $r$ increases, the negative effect of variance of the measurement error component is reduced. Next, the Phase II asymptotic control limits of the HWMA $\bar{X}^{*}$ scheme with $r$-measurements are defined by:

$$
U C L / L C L=\hat{\mu}_{0} \pm L^{*} \sqrt{\lambda^{2}\left(\frac{\hat{\sigma}_{0}^{2}}{n}+\frac{C+D \hat{\mu}_{0}}{n r}\right)} .
$$


To conserve space, in this paper, the focus is on the time-varying case.

\section{Performance of the HWMA $\bar{X}^{*}$ scheme in Case $U$ with measurement errors}

\subsection{Run-length metrics}

The average run-length $(A R L)$, defined as the mean of the run-length $(\mathrm{RL})$ distribution or the average number of rational subgroups plotted on a control chart before it gives a signal for the first time, is the most used RL metric in SPM literature. This metric reveals the degree of the sensitivity of a monitoring scheme towards specific shifts. To compute the RL properties (i.e. the $A R L$ and the standard deviation of the RL (SDRL)), in this paper, the Monte Carlo simulations approach using SAS v9.4 are used. Note that in addition to the latter, the expected $A R L(E A R L)$ metric is also used to investigate the performance over a range of shifts. The EARL is mathematically defined by

$$
E A R L_{\delta_{\min }, \delta_{\max }}=\frac{1}{\Delta} \sum_{\delta=\delta_{\min }}^{\delta_{\max }} A R L(\delta),
$$

where $\delta_{\min }$ and $\delta_{\max }$ are the lower and upper bound of the shift $(\delta)$ parameter, respectively, $A R L(\delta)$ is the $A R L$ value for a specific shift $\delta$ and $\Delta$ represents the number of increments between $\delta_{\min }$ and $\delta_{\max }$. Thus, the $E A R L$ values denoted by $E A R L_{0,1}, E A R L_{1,2}, E A R L_{2,3}$, $E A R L_{0,2}, E A R L_{1,3}$ and $E A R L_{0,3}$ are used to investigate the performance of the HWMA $\bar{X}^{*}$ scheme for small $(0<\delta \leq 1)$, moderate $(1<\delta \leq 2)$, large $(2<\delta \leq 3)$, small-to-moderate $(0<\delta \leq 2)$, moderate-to-large $(1<\delta \leq 3)$ and small-to-large $(0<\delta \leq 3)$ shifts, respectively.

\subsection{Sensitivity analysis}

In this section, the effects of both parameter estimation and measurement errors on the performance of the HWMA $\bar{X}^{*}$ scheme (under the assumption of normality) are investigated in terms of the $A R L$ and $S D R L$ profiles for specific shifts and EARL profile for different ranges of shifts. Table 1 presents the ARL and EARL profiles of the HWMA $\bar{X}^{*}$ scheme for Case $U$ when $m=20, \lambda \in\{0.1,0.5,0.9\}, \gamma \in\{0,0.2,0.5,0.9\}$ and $r=1 \& 4$ for a nominal $A R L_{0}$ of 500 . From Table 1, the following is observed:

- Measurement errors have a negative effect on the sensitivity of the HWMA $\bar{X}^{*}$ scheme, which means the higher the value of $\gamma$, the higher the values of the $A R L_{1}$ profile. For instance, when $\lambda=0.1, r=1$ and $\delta=0.25$, if $\gamma=0,0.2,0.5$ and 0.9 , the HWMA $\bar{X}^{*}$ scheme is expected to give a signal on the $311^{\text {th }}, 313^{\text {th }}, 336^{\text {th }}$ and $371^{\text {th }}$ sampling points, respectively. 
- When $\gamma$ is kept fixed, the HWMA $\bar{X}^{*}$ scheme is more sensitive to small values of $\lambda$, see for example the $E A R L_{0,1}$ values, where $\lambda=0.1$ yields the best performance than $\lambda$ equal to 0.5 and 0.9 , for each $\gamma$. For small-to-moderate (i.e. $E A R L_{0,2}$ ), moderate-tolarge (i.e. $E A R L_{1,3}$ ) as well as from small-to-large (i.e. $E A R L_{0,3}$ ) shifts, the HWMA $\bar{X}^{*}$ scheme performs better for small shifts and small values of $\lambda$. For instance, when $\gamma=0.5$ and $r=1$, for $\lambda=0.1,0.5$ and 0.9 , the HWMA $\bar{X}^{*}$ scheme is expected to give the first signal on the $16^{\text {th }}, 29^{\text {th }}$ and $78^{\text {th }}$ subgroups when $\delta=1$, respectively.

- Multiple measurements have a positive impact on the sensitivity of the HWMA $\bar{X}^{*}$ scheme. For instance, for $\lambda=0.1, \gamma=0.9$ and $\delta=0.25$, when $r=1$, the OOC $A R L$ (denoted as $A R L_{1}$ ) is equal to 371.62 ; however, when $r=4$, the $A R L_{1}$ is reduced to 336.03. This shows that a multiple measurements strategy reduces the negative effect of measurement errors.

- The design parameter $L^{*}$ decreases as $\lambda$ increases; which means, the larger the smoothing parameter, the narrower the control limits.

\section{$<$ Insert Table 1 here $>$}

As Table 1 is only constructed for $m=20$, other values of $m \in\{20,40,100, \infty\}$ are considered in Figure 1. Note that $m=\infty$ corresponds to the HWMA $\bar{X}^{*}$ scheme in Case K. It is observed that the lower the values of $m$, the higher the $A R L_{1}$ values. Stated differently, an increase in the Phase I sample size leads to an improved Phase II OOC performance of the HWMA $\bar{X}^{*}$ scheme. Thus, this shows that the HWMA $\bar{X}^{*}$ scheme is more sensitive when the process parameters are known; or stated differently, parameter estimation degrades Phase II OOC performance. Moreover, increasing $r$ from 1 to 4 leads to an improved Phase II OOC performance since the $A R L_{1}$ values are slightly reduced for all shift values.

$<$ Insert Figure 1 here $>$

Next, in Figure 2, it is apparent that at any shift value, the higher the value of $\lambda$, the poorer is the performance of the HWMA $\bar{X}^{*}$ scheme because the $A R L_{1}$ are larger than the corresponding lower values of $\lambda$. Stated differently, for the best performance in the HWMA $\bar{X}^{*}$ scheme, user are advised to use small values of $\lambda$. Moreover, increasing $r$ from 1 to 4 leads to an improved performance since the $A R L_{1}$ values are reduced for all shift values.

$<$ Insert Figure 2 here $>$

The effect of increasing $r$ on the $A R L$ and SDRL profiles is illustrated in Figure 3. It is shown that, in general, as $r$ increases the corresponding $A R L_{1}$ and the OOC SDRL (denoted by 
$\left.S D R L_{1}\right)$ values decrease at a slow rate. Also, the sensitivity pattern of the $S D R L_{1}$ profiles is similar to the one of the $A R L_{1}$.

$<$ Insert Figure 3 here $>$

Table 1 and Figures 1 to 3, show that when $\lambda$ and $\gamma$ are both large with a small value of $m$, the combined effect of measurement errors and parameter estimation significantly deteriorates the sensitivity of the HWMA $\bar{X}^{*}$ scheme. Hence, the smaller the values of $\lambda$ and $\gamma$, with a large value of $m$, yields a better HWMA $\bar{X}^{*}$ scheme performance. Also, when $\gamma$ is kept fixed and $m<100$, the HWMA $\bar{X}^{*}$ scheme performs better for small value of $\lambda$; however, for large shifts, the sensitivity of the HWMA $\bar{X}^{*}$ scheme increases in the interval 0 $<\lambda \leq 0.5$ and decreases in the interval $0.5<\lambda<1$. Finally, when $\gamma=0$ and $m \geq 100$, the sensitivity of the HWMA $\bar{X}^{*}$ scheme increases in the interval $0<\lambda \leq 0.5$ and decreases in the interval $0.5<\lambda<1$ regardless of the size of the mean shift; however, when $\gamma \neq 0$, it is more sensitive for small values of $\lambda$ regardless of the size of the shift in the process mean.

For ease in studying the sensitivity of proposed scheme, the following comparison metrics are defined:

i. As measurement errors are known to have a negative effect on the sensitivity of a monitoring scheme, it is therefore important to investigate the percentage decrease in the performance of the proposed scheme for specific $\gamma(\gamma \neq 0)$ values compared to the case with perfect measurements (i.e. $\gamma=0$ ) when both $m$ and $r$ are fixed. Thus, the criterions quantifying the percentage decrease and its expected value are denoted as $\Delta_{\gamma}(\delta, r, m)$ and $\bar{\Delta}_{\gamma}(\delta, r, m)$, respectively, and they are computed using the following formulas:

$$
\Delta_{\gamma}(\delta, r, m)=\frac{A R L_{1}^{*}(\delta, r, m)-A R L_{1}(\delta, r, m)}{A R L_{1}(\delta, r, m)} \times 100
$$

and

$$
\bar{\Delta}_{\gamma}(\delta, r, m)=\frac{1}{\Delta} \sum_{\delta=\delta_{\min }}^{\delta_{\max }} \Delta_{\gamma}(\delta, r, m),
$$

where $A R L_{1}^{*}(\delta, r, m)$ is the OOC $A R L$ value of the HWMA $\bar{X}^{*}$ scheme for a specific shift when $\gamma \neq 0$ and $A R L_{1}(\delta, r, m)$ is the OOC $A R L$ value for a specific shift when $\gamma=0$.

ii. Multiple measurements help to reduce the negative effect of measurement errors. For a specific $\gamma(\gamma \neq 0)$ with 1-measurement (i.e. $r=1)$, there is a decrease in the performance of a monitoring scheme. However, if the values of $\gamma($ where $\gamma \neq 0)$ and 
$m$ are fixed and $r$ increases (i.e. $r>1$ ), they will be gain (or increase) in the performance compared to the situation where a single measurement is used under the same value of $\gamma$. Thus, the percentage increase in the performance and its expected value denoted as $\Delta_{r}(\delta, \gamma, m)$ and $\bar{\Delta}_{r}(\delta, \gamma, m)$, respectively, can be computed in a similar way using the following formula:

$$
\Delta_{r}(\delta, \gamma, m)=\left|\frac{A R L_{1}^{*}(\delta, \gamma, m)-A R L_{1}(\delta, \gamma, m)}{A R L_{1}(\delta, \gamma, m)}\right| \times 100
$$

and

$$
\bar{\Delta}_{r}(\delta, \gamma, m)=\frac{1}{\Delta} \sum_{\delta=\delta_{\min }}^{\delta_{\max }} \Delta_{r}(\delta, \gamma, m),
$$

where $A R L_{1}^{*}(\delta, \gamma, m)$ is the OOC $A R L$ value of the HWMA $\bar{X}^{*}$ scheme for a specific shift when $r>1$ and $A R L_{1}(\delta, \gamma, m)$ is the OOC $A R L$ value for a specific shift when $r=1$.

Figure 4 displays the $\Delta_{\gamma}(\delta, r, m)$ values when $r$ and $m$ are fixed for different values of $\lambda$ while Figure 5 displays the $\Delta_{r}(\delta, \gamma, m)$ values when $\gamma$ and $m$ are fixed. It is observed that the larger the value of $\gamma$, the higher the decrease in the sensitivity of the HWMA $\bar{X}^{*}$ scheme. From Figure 4, it can be seen that in Case $U$, for small values of $\lambda$, regardless of the level of measurement errors, the monitoring scheme under investigation reach a maximum decrease in its performance for a shift of size 0.5 standard deviation. For moderate values of $\lambda$, the maximum decrease in the performance is reached for shift of one standard deviation. For large values of $\lambda$, the maximum decrease in the sensitivity of the HWMA $\bar{X}^{*}$ scheme is reached when $\delta \in[1.75,2]$. From Figure 5 , it can be seen that regardless of the value of $\lambda$, the $\Delta_{r}(\delta, \gamma, m)$ value of the monitoring scheme under investigation is higher for large values of $r$ and it is more significant for higher level of measurement errors (see Figure 5 (c), (f) and (i)).

\section{$<$ Insert Figures 4 and 5 here $>$}

In the design of statistical monitoring schemes with measurement errors, it is very important to investigate the number measurements per sampling time necessary to compensate the negative effect of measurement errors. In most of the cases the elimination of the effect of measurement errors is almost impossible because the measurement costs need to be reduced and large sample size should be avoided. Figure 6 presents the marginal $\Delta_{r}(\delta, \gamma, m)$ (i.e., the percentage decrease in the $A R L_{1}$ value for one unit increase in the value of $r$ ) of the HWMA $\bar{X}^{*}$ scheme when using different sets of measurements with $\lambda=0.1$. Figure 6 shows that in Case $\mathrm{U}$, the marginal $\Delta_{r}(\delta, \gamma, m)$ decreases as the number of measurement increases. 
Therefore, for small level of measurement errors, it is advised to use 2 sets of measurements of size 5 because when $r=3$, the marginal $\Delta_{r}(\delta, \gamma, m)$ is below $1 \%$ which can be considered as insignificant. For moderate values of $\gamma$, it is advised to use $r$ equal to 3 or 4 and for large values of $\gamma$, the use of $r$ equal to 4 or 5 is advised. These recommendations hold for all values of $\lambda$.

$<$ Insert Figure 6 here $>$

Table 2 displays the performance of the HWMA $\bar{X}^{*}$ scheme for a linearly increasing population variance when $C=0,1,2,3$ (with $D=0$ ) and $D=0,1,2,3$ (with $C=0$ ) for $\lambda=0.1$ and with $r=1$ and ( $r=4$ in parentheses). For $D$ constant, it is observed that the sensitivity of the HWMA $\bar{X}^{*}$ scheme decreases as $C$ increases whenever $\delta>0$. For instance, when $r=1$ and $\delta=1.25$, then for $C=0,1,2$, and 3 , the HWMA $\bar{X}^{*}$ scheme gives a signal on the $7^{\text {th }}, 13^{\text {th }}, 18^{\text {th }}$ and $24^{\text {th }}$ sampling points, respectively. Moreover, when 4 measurements are used (i.e. $r=4$ in parentheses), the HWMA $\bar{X}^{*}$ scheme gives a signal on the $7^{\text {th }}, 8^{\text {th }}, 10^{\text {th }}$ and $11^{\text {th }}$ sampling points when $C=0,1,2$, and 3, respectively. Hence, increasing the number of measurements has a positive effect on the sensitivity of the HWMA $\bar{X}^{*}$ scheme by reducing the effect of measurement errors regardless of the degree of the linear increase in the process variance. Next, for $C$ constant, it is similarly observed that the sensitivity of the HWMA $\bar{X}^{*}$ scheme decreases as $D$ increases whenever $\delta>0$. For instance, when $r=1$ and $\delta=1.25$, then for $C=$ $0,1,2$, and 3 , the HWMA $\bar{X}^{*}$ scheme gives a signal on the $7^{\text {th }}, 13^{\text {th }}, 18^{\text {th }}$ and $23^{\text {th }}$ subgroups, respectively. Note that when $r$ increase, the HWMA $\bar{X}^{*}$ scheme improves in performance as the negative effect of measurement errors is reduced by taking multiple measurements. When $C=D=0$, there is no measurement error in the measurement system; hence, there is no need to increase $r$ as it yields no improvement in the performance of the monitoring scheme, i.e. the $A R L_{1}$ are the same for any values of $r$. Finally, although not shown in Table 2, increasing $\lambda$ has a similar effect in performance as that observed in Table 1; that is, the higher the value of the smoothing parameter the worse the performance gets for the linearly increasing variance scenario.

\section{$<$ Insert Table 2 here $>$}

\subsection{Robustness of HWMA $\bar{X}^{*}$ scheme}

A monitoring scheme is said to be IC robust if the IC characteristics of the run-length distribution are the same or significantly close across all continuous distributions. To check this, in Table 3, the $A R L_{0}$ and $A R L_{1}$ values are computed for some symmetrical and skewed distributions. The considered distributions are: 
(i) Standard normal distribution, i.e. $N(0,1)$.

(ii) Student's $t$ distribution with degrees of freedom $v=5,10,20$; i.e. $t(5), t(10), t(20)$.

(iii) Gamma distribution with parameters $\omega=1,3,10$ and $\beta=1$; i.e. $\operatorname{GAM}(1,1)$, $\operatorname{GAM}(3,1), \operatorname{GAM}(10,1)$.

(iv) Standard double exponential distribution with $\mu=0$ and $\beta=1$, denoted $\operatorname{DEXP}(0,1)$.

For a fair comparison, the above distributions are transformed such that the mean and standard deviation are equal to 0 and 1 , respectively. To check the IC robustness and OOC behavior of the proposed HWMA $\bar{X}$ scheme, the IC and OOC characteristics of the run-length distribution were computed using Monte Carlo simulations. To preserve writing space, Table 3 displays the attained $A R L$ values only. For different values of $m$, it is apparent that the HWMA $\bar{X}^{*}$ scheme is not IC robust for some non-normal distributions. That is, based on the IC ARL values, the following findings can be observed from Table 3:

- Regardless of the Phase I sample size, the proposed HWMA $\bar{X}^{*}$ scheme is IC robust under the normal distribution because the attained $A R L$ is approximately equal to the nominal $A R L$

- Under the $t(v)$ distributions, regardless of the Phase I sample size (including the Case K) the HWMA $\bar{X}^{*}$ scheme is not IC robust for small degrees of freedom (v) because the attained $A R L$ is not equal to the nominal $A R L$. However, as $v$ increases the HWMA $\bar{X}^{*}$ scheme tends towards IC robustness. Additional simulations, not shown in Table 3, indicate that IC robustness is achieved when $v$ is larger than 30. It is worth mentioning that the $t(v)$ distribution (with $v>30$ ) is approximately equal to the normal distribution.

- Similar to the $t(v)$ distribution, under the $\operatorname{GAM}(\omega, 1)$ distribution, the HWMA $\bar{X}^{*}$ scheme is only IC robust when the shape parameter is large (i.e., $\omega>10$ ); however, it is not IC robust when $\omega<10$.

- Under the standard $\operatorname{DEXP}(0,1)$ distribution, the HWMA $\bar{X}^{*}$ scheme is not IC robust.

In general, it is observed from Table 3 that for different underlying distributions, the IC $A R L$ values are not approximately the same and thus, the HWMA $\bar{X}^{*}$ scheme is not IC robust. Finally, all the distributions in Table 3 have a similar OOC performance for moderate-tolarge shifts, except for the standard $\operatorname{DEXP}(0,1)$ distribution which is observed to have the worst performance for all considered values of $m$.

$<$ Insert Table 3 here $>$

\subsection{Comparison with other memory-type schemes}


As far as we know, no GWMA $\bar{X}^{*}$ scheme to monitor the process mean under the effect of measurement errors does exist in the SPM literature for Cases $\mathrm{K}$ and U. The EWMA and CUSUM $\bar{X}^{*}$ schemes in Case $\mathrm{K}$ are discussed in [32] and [33], respectively; however, the Case U versions do not exist in the SPM literature. The latter three monitoring schemes in Case $U$ are in part, discussed in this section. Thus, the proposed HWMA $\bar{X}^{*}$ scheme is compared to the CUSUM, EWMA and GWMA $\bar{X}^{*}$ schemes under the effect of both measurement errors and parameter estimation under the normality assumption. To compare the sensitivity of the competing schemes, the performance of each scheme is investigated when $(m, n)=(100,5), r \in\{1,4\}$ and $\gamma \in\{0,0.2,0.5,0.9\}$. Therefore, for an attained $A R L_{0}$ of 500 , it is found that the combinations of the design parameters of the CUSUM and EWMA $\bar{X}^{*}$ schemes are $\left(k_{C}, h_{C}\right)=(0.125,6.729)$ and $\left(\lambda_{E}, L_{E}\right)=(0.1,2.938)$, respectively, and those of the GWMA $\bar{X}^{*}$ scheme are $\left(\alpha, q, L_{G}\right)=(0.5,0.9,3.336)$ where $q=1-\lambda_{E}$. These design parameters yield attained $A R L_{0}$ values as close as possible to 500 .

Table 4 displays the $A R L$ and EARL values of the HWMA, CUSUM, EWMA and GWMA $\bar{X}^{*}$ schemes for different values of $\gamma$ and $r$. From this table, at each shift value or range of shift values, the best performing scheme is boldfaced. It can be seen that, regardless of the level of measurement error or the number of measurements, the HWMA $\bar{X}^{*}$ scheme outperforms the CUSUM, EWMA and GWMA $\bar{X}^{*}$ schemes under small mean shifts. The GWMA $\bar{X}^{*}$ scheme with small values of $\alpha$ is superior to both CUSUM and EWMA $\bar{X}^{*}$ schemes for very small shifts (i.e., $0<\delta \leq 0.25)$. However, when $\delta \in(0.25,3]$, the EWMA $\bar{X}^{*}$ scheme (which is equivalent to the GWMA $\bar{X}^{*}$ scheme with $\alpha=1$ ) outperforms both the HWMA and CUSUM $\bar{X}^{*}$ schemes. For moderate and large shifts (see $E A R L_{1,2}$ and $E A R L_{2,3}$ ), as well as moderateto-large shifts (see $E A R L_{1,3}$ ), the EWMA $\bar{X}^{*}$ scheme performs better than the GWMA, CUSUM and HWMA $\bar{X}^{*}$ schemes. Next, with respect to the EARLs, the CUSUM $\bar{X}^{*}$ scheme seems to yield the worst OOC performance when compared to its memory-type competitors. For small-to-moderate and small-to-large shifts (see $E A R L_{0,2}$ and $E A R L_{0,3}$ ) as well as for small shifts only (see $E A R L_{0,2}$ ), the HWMA $\bar{X}^{*}$ scheme is superior to all its competing memory-type monitoring schemes. In essence, the latter deduction implies that the proposed HWMA $\bar{X}^{*}$ scheme is expected to yield better detection ability than its real-world competitors (i.e. CUSUM, EWMA and GWMA schemes) for most shift values in the process mean when a user is more interested in: (i) small shifts only, (ii) a range of small to moderate shifts, and (iii) a range of small to large shifts. 


\section{Illustrative example}

In order to illustrate the implementation of the HWMA $\bar{X}^{*}$ scheme with measurement error under the assumption of unknown process parameters, the data from [34] which is shown in Table 5 are used as the Phase II data. The dataset is based on a yogurt cup filling process where the quality characteristic $X_{t, i, j}^{*}$ is the weight of each yogurt cup. In this example, it is assumed that the IC mean and the IC standard deviation are unknown and they are estimated from the Phase I sample of size 100 (i.e. $m=100$ ). Hence, using (6) yields $\hat{\mu}_{0}=124.90 \mathrm{~g}$, $s=0.76, c_{4,100}=0.9994$ and $\hat{\sigma}_{0}=0.76 / 0.9994=0.7605 \mathrm{~g}$. An independent R\&R study estimated the measurement standard deviation $\sigma_{M}=0.24$ and thus, $\gamma=0.24 / 0.7605=0.3156$. The quality practitioner in charge of this process decided to take, every hour, two sets of measurements, each of size 5 (i.e. $r=2$ and $n=5$ ). For a nominal $A R L_{0}$ value of 500 and $\lambda=$ 0.1 , it is found that $L^{*}=3.32$ yields an attained $A R L_{0}$ of 501.26. Thus, when $r=2$, the lower and upper control limits of the HWMA $\bar{X}^{*}$ scheme when $t=1$ and 2 are calculated using (11) as follows:

$$
L C L_{t}= \begin{cases}124.90-3.32 \sqrt{\frac{0.1^{2} \times(0.7605)^{2}}{5}\left(1+\frac{(0.3156)^{2}}{2}\right)}=124.78, & t=1 \\ 124.90-3.32 \sqrt{\left(\frac{0.1^{2} \times(0.7605)^{2}}{5}+\frac{(1-0.1)^{2} \times(0.7605)^{2}}{5 \times(2-1)}\right)\left(1+\frac{(0.3156)^{2}}{2}\right)}=123.85, & t=2\end{cases}
$$

and

$$
U C L_{t}=\left\{\begin{array}{l}
124.90+3.32 \sqrt{\frac{0.1^{2} \times(0.7605)^{2}}{5}\left(1+\frac{(0.3156)^{2}}{2}\right)}=125.02, \\
124.90+3.32 \sqrt{\left(\frac{0.1^{2} \times(0.7605)^{2}}{5}+\frac{(1-0.1)^{2} \times(0.7605)^{2}}{5 \times(2-1)}\right)\left(1+\frac{(0.3156)^{2}}{2}\right)}=125.95 . t=2 .
\end{array}\right.
$$

For $t>2$, the rest of the time-varying control limits can also be calculated in a similar way as shown in Equations (16b) and (17b), respectively. For illustration purpose, the first three plotting statistics are calculated as follows:

$$
\begin{gathered}
\bar{X}_{1}^{*}=\frac{124.9+125.9+\cdots+124.1+124.4}{10}=124.94 \text { and } \overline{\bar{X}}_{0}^{*}=\hat{\mu}_{0}=124.9, \\
\bar{X}_{2}^{*}=\frac{124.9+125.5+\cdots+125.2+125.6}{10}=124.96 \text { and } \overline{\bar{X}}_{1}^{*}=\frac{\bar{X}_{1}^{*}}{1}=124.94, \\
\bar{X}_{3}^{*}=\frac{125.1+125.2+\cdots+122.4+125.4}{10}=124.70 \text { and } \overline{\bar{X}}_{2}^{*}=\frac{\bar{X}_{1}^{*}+\bar{X}_{2}^{*}}{2}=\frac{124.94+124.96}{2}=124.95,
\end{gathered}
$$

so that,

$$
\begin{aligned}
& H_{1}^{*}=\lambda \bar{X}_{1}^{*}+(1-\lambda) \overline{\bar{X}}_{0}^{*}=0.1(124.94)+(1-0.1) 124.9=124.90 \\
& H_{2}^{*}=\lambda \bar{X}_{2}^{*}+(1-\lambda) \overline{\bar{X}}_{1}^{*}=0.1(124.96)+(1-0.1) 124.94=124.94
\end{aligned}
$$




$$
H_{3}^{*}=\lambda \bar{X}_{3}^{*}+(1-\lambda) \overline{\bar{X}}_{2}^{*}=0.1(124.70)+(1-0.1) 124.95=124.93 .
$$

The rest of the plotting statistics of the HWMA $\bar{X}^{*}$ scheme with 2-measurements are empirically shown in Table 5 and graphically in Figure 7. It is observed that the HWMA $\bar{X}^{*}$ scheme give an OOC signal for the first time on the $14^{\text {th }}$ subgroup.

$$
\begin{aligned}
& <\text { Insert Table } 5 \text { here }> \\
& <\text { Insert Figure } 7 \text { here }>
\end{aligned}
$$

\section{Conclusion}

Most of the monitoring schemes are based on the assumption of Case $\mathrm{K}$ and perfect measurements. This paper proposes the HWMA scheme in Case U under the assumption of perfect and imperfect measurements. It is observed that the sensitivity of the HWMA scheme deteriorate significantly when the level of measurement error increases and the use of multiple measurements has a positive effect on the sensitivity. The negative effect of the measurement errors is more pronounced when there is a linearly increasing variance than when the error variance is constant. Note though, practitioners are not advised to use more than five measurements in the design of the HWMA scheme regardless of the level of the measurement error. Also, it is shown that the HWMA $\bar{X}^{*}$ scheme is not IC robust and higher values of the smoothing parameter lead to poor Phase II OOC performance. Moreover, as the Phase I sample size increases, the performance of the HWMA scheme in Phase II improves. In comparison to the CUSUM scheme, the HWMA scheme is found to be superior regardless of the size of the mean shift. In addition, the HWMA scheme is superior to the EWMA and GWMA schemes under small shifts; however, for moderate-to-large shifts, the converse is true. Therefore, given the fact that the HWMA scheme has a simpler design model and has a competitive performance compared to the EWMA and GWMA schemes, practitioners are recommended to rather use the HWMA scheme to monitor the process mean with or without measurement errors.

Note that the HWMA scheme is designed under the effect of measurement errors only. Therefore, for future research, the combined effect of measurement errors and autocorrelation need to be investigated in both Cases K and U. So far, no HWMA-type scheme based on attributes data exist, this needs to be addressed. In this paper, an additive error model is implemented, for future research, a two- or three-component error model can also be investigated for the HWMA scheme; see for instance [35] where the two-component error model is implemented for the EWMA scheme. 


\section{References}

[1] Montgomery DC. Statistical Quality Control: A Modern Introduction, $6^{\text {th }}$ ed., John Wiley \& Sons: Singapore Pte. Ltd, 2009.

[2] Qiu, P. Introduction to Statistical Process Control. Chapman \& Hall/CRC Press, Taylor \& Francis Group, Baton Rouge: Florida, 2014.

[3] Aslam M, Saghir A, Ahmad L. Introduction to Statistical Process Control, Wiley: New York, 2020.

[4] Noor-ul-Amin M, Tayyab M. Enhancing the performance of exponential weighted moving average control chart using paired double ranked set sampling. J Stat Comput Simul. 2020; 90(6):1118-1130.

[5] Awais M, Haq A. An EWMA chart for monitoring the process mean. J Stat Comput Simul. 2018; 88(5):1003-1025.

[6] Mabude K., Malela-Majika J-C, Castagliola P, et al. Generally weighted moving average monitoring schemes - Overview and Perspectives. Qual Reliab Eng Int. 2020; DOI: 10.1002 /qre. 2765 .

[7] Abbas N. Homogeneously weighted moving average control chart with an application in substrate manufacturing process. Comp Industr Eng. 2018;120:460-470.

[8] Adegoke NA, Smith ANH, Anderson MJ, et al. Efficient homogeneously weighted moving average chart for monitoring process mean using an auxiliary variable. IEEE Access. 2019;7:94021-94032.

[9] Nawaz T, Han D. Monitoring the process location by using new ranked set sampling based memory control charts. Qual Tech Quant Manag. 2020; 17(3):255-284.

[10] Abid M, Shabbir A, Nazir HZ, et al. A double homogeneously weighted moving average control chart for monitoring of the process mean. Qual Reliab Eng Int. 2020; 36(5):1513-1527.

[11] Adeoti OA, Koleoso SO. A hybrid homogeneously weighted moving average control chart for process monitoring. Qual Reliab Eng Int. 2020; 36(6):2170-2186.

[12] Abid M, Mei S, Nazir HZ, et al. A mixed HWMA-CUSUM mean chart with an application to manufacturing process. Qual Reliab Eng Int. 2020; DOI: 10.1002/qre.2752.

[13] Dawod A, Adegoke NA, Abbasi SA. Efficient linear profile schemes for monitoring bivariate correlated processes with applications in the pharmaceutical industry. Chem Lab Syst. 2020; 206:104137.

[14] Adegoke NA, Abbasi SA, Smith ANH, et al. A multivariate homogeneously weighted moving average control chart. IEEE Access, 2019;7:9586-9597.

[15] Abbas N, Riaz M, Ahmad S, et al. On the efficient monitoring of multivariate processes with unknown parameters. Mathematics, 2020; 8(5):823. DOI: 10.3390/math8050823.

[16] Raza M, Nawaz T, Han D. On designing distribution-free homogeneously weighted moving average control charts. J Test Eval. 2020; 48(4):3154-3171.

[17] Mehmood R, Qazi MS, Riaz M. On the performance of $\bar{X}$ control chart for known and unknown parameters supplemented with runs rules under different probability distributions. J Stat Comput Simul. 2018; 88(4):675-711.

[18] $\mathrm{Hu}$ XL, Castagliola P, Tang AA. Conditional design of the CUSUM median chart for the process position when process parameters are unknown. J Stat Comput Simul. 2019; 89(13):2468-2488.

[19] Mehmood R, Lee MH, Afzel A, et al. Generalized skewness correction structure of $\bar{X}$ control chart for unknown process parameters and skewed probability distributions. $\mathrm{J}$ Stat Comput Simul. 2020; 90(8):1349-1372. 
[20] Does RJMM, Goedhart R, Woodall WH. On the design of control charts with guaranteed conditional performance under estimated parameters. Qual Reliab Eng Int. 2020; DOI: 10.1002/qre.2658.

[21] Maleki MR, Amiri A, Castagliola P. Measurement errors in statistical process monitoring: A literature review. Comp Industr Eng. 2017;103:316-329.

[22] Linna KW, Woodall WH. Effect of measurement error on Shewhart control charts. J Qual Tech. 2001;33(2):213-222.

[23] Cheng X-B, Wang F-K. VSSI median control chart with estimated parameters and measurement errors. Qual Reliab Eng Int. 2018;34(5):867-881.

[24] Tang AA, Castagliola P, Hu XL, et al. The performance of the adaptive EWMA median chart in the presence of measurement error. Qual Reliab Eng Int. 2019;35(1):423-438.

[25] Riaz A, Noor-ul-Amin M, Shehzad MA, et al. Auxiliary information based mixed EWMA-CUSUM mean control chart with measurement error. Iranian J Sci Tech, Trans A: Sc. 2019;43(6):2937-2949.

[26] Shongwe SC, Malela-Majika J-C, Castagliola P. A combined mixed-s-skip sampling strategy to reduce the effect of autocorrelation on the $\bar{X}$ scheme with and without measurement errors. J Appl Stat. 2020; DOI: 10.1080/02664763.2020.1759033.

[27] Saha S, Khoo MBC, Castagliola P, et al. Side-sensitive modified group runs charts with and without measurement errors for monitoring the coefficient of variation. Qual Reliab Eng Int. 2020; DOI:10.1002/qre.2751.

[28] Tran PH, Heuchenne C, Nguyen H-D, et al. Monitoring coefficient of variation using one-sided run rules control charts in the presence of measurement errors. J Appl Stat. 2020; DOI: 10.1080/02664763.2020.1787356.

[29] Asif F, Khan S, Noor-ul-Amin M. Hybrid exponentially weighted moving average control chart with measurement error. Iranian J Sci Tech, Trans A: Sc. 2020; 44 (3): 801-811.

[30] Noor-ul-Amin M, Javaid A, Hanif M, et al. Performance of maximum EWMA control chart in the presence of measurement error using auxiliary information. Comm Stat Simul Comput. 2020; DOI: 10.1080/03610918.2020.1772301.

[31] Nguyen H-D, Tran KP, Celano G, et al. On the effect of the measurement error on Shewhart $t$ and EWMA $t$ control charts. Int J Adv Manuf Tech. 2020; 107 (1-4): $4317-$ 4332.

[32] Maravelakis P, Panaretos J, Psarakis S. EWMA chart and measurement error. J Appl Stat. 2004;31(4):445-455.

[33] Maravelakis P. Measurement error on the CUSUM control chart. J Appl Stat. 2012;39(2):323-336.

[34] Costa AFB, Castagliola P. Effect of measurement error and autocorrelation on the $\bar{X}$ chart. J Appl Stat. 2011;38(4):661-673.

[35] Abbasi SA. Exponentially weighted moving average chart and two-component measurement error. Qual Reliab Eng Int. 2016;32(2):499-504. 
Table 1: The $A R L$ and $E A R L$ profiles of the HWMA $\bar{X}^{*}$ scheme in Case $\mathrm{U}$ when $A=0, B=1$, $m=20, n=5, \lambda \in\{0.1,0.5,0.9\}$ and $\gamma \in\{0,0.2,0.5,0.9\}$ with $r=1$ (and $r=4$ in parenthesis)

\begin{tabular}{|c|c|c|c|c|c|c|c|c|c|c|c|c|}
\hline \multirow[b]{2}{*}{ Shift } & \multicolumn{4}{|c|}{$\lambda=0.1$} & \multicolumn{4}{|c|}{$\lambda=0.5$} & \multicolumn{4}{|c|}{$\lambda=0.9$} \\
\hline & $\gamma=\mathbf{0}$ & $\gamma=0.2$ & $\gamma=0.5$ & $\gamma=0.9$ & $\gamma=0$ & $\gamma=0.2$ & $\gamma=0.5$ & $\gamma=0.9$ & $\gamma=0$ & $\gamma=0.2$ & $\gamma=0.5$ & $\gamma=0.9$ \\
\hline 0.00 & 500.74 & 500.74 & 500.74 & 500.74 & 504.10 & 504.10 & 504.10 & 504.10 & 507.69 & 507.69 & 507.69 & 507.69 \\
\hline 0.25 & 311.14 & $\begin{array}{c}313.21 \\
(305.44) \\
\end{array}$ & $\begin{array}{c}336.16 \\
(315.82) \\
\end{array}$ & $\begin{array}{c}371.62 \\
(336.03) \\
\end{array}$ & 363.23 & $\begin{array}{c}369.05 \\
(360.63) \\
\end{array}$ & $\begin{array}{c}385.32 \\
(367.39) \\
\end{array}$ & $\begin{array}{c}418.20 \\
(380.59) \\
\end{array}$ & 414.79 & $\begin{array}{c}415.23 \\
(413.74) \\
\end{array}$ & $\begin{array}{c}429.07 \\
(414.71)\end{array}$ & $\begin{array}{c}446.72 \\
(429.10) \\
\end{array}$ \\
\hline 0.5 & 88.26 & $\begin{array}{c}92.25 \\
(88.39) \\
\end{array}$ & $\begin{array}{r}118.82 \\
(96.08) \\
\end{array}$ & $\begin{array}{c}178.38 \\
(115.74)\end{array}$ & 150.76 & $\begin{array}{c}159.14 \\
(151.95)\end{array}$ & $\begin{array}{c}189.00 \\
(162.91)\end{array}$ & $\begin{array}{c}249.84 \\
(181.71)\end{array}$ & 243.78 & $\begin{array}{l}246.99 \\
(243.3)\end{array}$ & $\begin{array}{c}278.81 \\
(250.80)\end{array}$ & $\begin{array}{c}327.88 \\
(268.16) \\
\end{array}$ \\
\hline 0.75 & 26.54 & $\begin{array}{c}27.50 \\
(26.12) \\
\end{array}$ & $\begin{array}{c}37.99 \\
(28.01) \\
\end{array}$ & $\begin{array}{c}63.56 \\
(33.69) \\
\end{array}$ & 52.37 & $\begin{array}{c}55.52 \\
(53.72) \\
\end{array}$ & $\begin{array}{c}72.51 \\
(56.82) \\
\end{array}$ & $\begin{array}{l}121.30 \\
(68.89) \\
\end{array}$ & 118.85 & $\begin{array}{c}122.56 \\
(118.89) \\
\end{array}$ & $\begin{array}{c}149.61 \\
(127.44) \\
\end{array}$ & $\begin{array}{c}206.41 \\
(145.83) \\
\end{array}$ \\
\hline 1.00 & 13.09 & $\begin{array}{c}13.57 \\
(13.22)\end{array}$ & $\begin{array}{c}16.47 \\
(13.86)\end{array}$ & $\begin{array}{c}26.79 \\
(15.89)\end{array}$ & 20.56 & $\begin{array}{c}22.27 \\
(21.32)\end{array}$ & $\begin{array}{c}29.44 \\
(22.93)\end{array}$ & $\begin{array}{c}54.33 \\
(27.94)\end{array}$ & 58.25 & $\begin{array}{c}60.88 \\
(59.23)\end{array}$ & $\begin{array}{c}78.51 \\
(62.46)\end{array}$ & $\begin{array}{r}121.36 \\
(75.04)\end{array}$ \\
\hline 1.25 & 8.46 & $\begin{array}{c}8.79 \\
(8.55) \\
\end{array}$ & $\begin{array}{l}10.43 \\
(8.94) \\
\end{array}$ & $\begin{array}{c}15.21 \\
(10.02) \\
\end{array}$ & 10.67 & $\begin{array}{c}11.23 \\
(10.80) \\
\end{array}$ & $\begin{array}{c}14.65 \\
(11.57) \\
\end{array}$ & $\begin{array}{c}26.14 \\
(14.10) \\
\end{array}$ & 29.84 & $\begin{array}{c}31.48 \\
(30.16) \\
\end{array}$ & $\begin{array}{c}42.33 \\
(32.89) \\
\end{array}$ & $\begin{array}{c}71.82 \\
(39.69) \\
\end{array}$ \\
\hline 1.5 & 6.17 & $\begin{array}{c}6.39 \\
(6.23) \\
\end{array}$ & $\begin{array}{c}7.47 \\
(6.52) \\
\end{array}$ & $\begin{array}{l}10.55 \\
(7.21) \\
\end{array}$ & 6.54 & $\begin{array}{c}6.84 \\
(6.64) \\
\end{array}$ & $\begin{array}{c}8.71 \\
(7.08) \\
\end{array}$ & $\begin{array}{l}14.92 \\
(8.31) \\
\end{array}$ & 16.55 & $\begin{array}{c}17.65 \\
(16.72) \\
\end{array}$ & $\begin{array}{c}23.75 \\
(18.22) \\
\end{array}$ & $\begin{array}{c}42.13 \\
(22.32) \\
\end{array}$ \\
\hline 1.75 & 4.81 & $\begin{array}{c}4.95 \\
(4.86) \\
\end{array}$ & $\begin{array}{c}5.76 \\
(5.04) \\
\end{array}$ & $\begin{array}{c}7.87 \\
(5.58) \\
\end{array}$ & 4.58 & $\begin{array}{c}4.76 \\
(4.59) \\
\end{array}$ & $\begin{array}{c}5.89 \\
(4.85) \\
\end{array}$ & $\begin{array}{c}9.55 \\
(5.63) \\
\end{array}$ & 9.91 & $\begin{array}{c}10.41 \\
(10.05) \\
\end{array}$ & $\begin{array}{c}14.38 \\
(10.91) \\
\end{array}$ & $\begin{array}{c}26.23 \\
(13.51) \\
\end{array}$ \\
\hline 2.00 & 3.95 & $\begin{array}{c}4.05 \\
(3.98)\end{array}$ & $\begin{array}{c}4.66 \\
(4.11)\end{array}$ & $\begin{array}{c}6.29 \\
(4.50)\end{array}$ & 3.44 & $\begin{array}{c}3.58 \\
(3.46)\end{array}$ & $\begin{array}{c}4.35 \\
(3.64)\end{array}$ & $\begin{array}{c}6.75 \\
(4.16)\end{array}$ & 6.39 & $\begin{array}{c}6.75 \\
(6.43)\end{array}$ & $\begin{array}{c}9.27 \\
(7.03)\end{array}$ & $\begin{array}{l}16.97 \\
(8.60)\end{array}$ \\
\hline 2.25 & 3.33 & $\begin{array}{c}3.42 \\
(3.36) \\
\end{array}$ & $\begin{array}{c}3.90 \\
(3.47) \\
\end{array}$ & $\begin{array}{c}5.19 \\
(3.80) \\
\end{array}$ & 2.75 & $\begin{array}{c}2.85 \\
(2.76) \\
\end{array}$ & $\begin{array}{c}3.40 \\
(2.90) \\
\end{array}$ & $\begin{array}{c}5.04 \\
(3.27) \\
\end{array}$ & 4.38 & $\begin{array}{c}4.65 \\
(4.45) \\
\end{array}$ & $\begin{array}{c}6.23 \\
(4.82) \\
\end{array}$ & $\begin{array}{l}11.42 \\
(5.84) \\
\end{array}$ \\
\hline 2.5 & 2.87 & $\begin{array}{c}2.96 \\
(2.90) \\
\end{array}$ & $\begin{array}{c}3.36 \\
(3.00) \\
\end{array}$ & $\begin{array}{c}4.39 \\
(3.27) \\
\end{array}$ & 2.29 & $\begin{array}{c}2.37 \\
(2.30) \\
\end{array}$ & $\begin{array}{c}2.78 \\
(2.41) \\
\end{array}$ & $\begin{array}{c}3.99 \\
(2.68) \\
\end{array}$ & 3.23 & $\begin{array}{c}3.41 \\
(3.26) \\
\end{array}$ & $\begin{array}{c}4.46 \\
(3.50) \\
\end{array}$ & $\begin{array}{c}8.13 \\
(4.25) \\
\end{array}$ \\
\hline 2.75 & 2.51 & $\begin{array}{c}2.59 \\
(2.53) \\
\end{array}$ & $\begin{array}{c}2.95 \\
(2.62) \\
\end{array}$ & $\begin{array}{c}3.82 \\
(2.86) \\
\end{array}$ & 1.96 & $\begin{array}{c}2.02 \\
(1.97) \\
\end{array}$ & $\begin{array}{c}2.34 \\
(2.05) \\
\end{array}$ & $\begin{array}{c}3.29 \\
(2.27) \\
\end{array}$ & 2.50 & $\begin{array}{c}2.62 \\
(2.52) \\
\end{array}$ & $\begin{array}{c}3.39 \\
(2.68) \\
\end{array}$ & $\begin{array}{c}5.99 \\
(3.17) \\
\end{array}$ \\
\hline 3.00 & 2.20 & $\begin{array}{c}2.27 \\
(2.22) \\
\end{array}$ & $\begin{array}{c}2.61 \\
(2.30) \\
\end{array}$ & $\begin{array}{c}3.36 \\
(2.53) \\
\end{array}$ & 1.72 & $\begin{array}{c}1.77 \\
(1.74) \\
\end{array}$ & $\begin{array}{c}2.03 \\
(1.80) \\
\end{array}$ & $\begin{array}{c}2.80 \\
(1.98) \\
\end{array}$ & 2.00 & $\begin{array}{c}2.11 \\
(2.03) \\
\end{array}$ & $\begin{array}{c}2.65 \\
(2.16) \\
\end{array}$ & $\begin{array}{c}4.49 \\
(2.52) \\
\end{array}$ \\
\hline$E A R L_{0,1}$ & 109.76 & $\begin{array}{c}111.63 \\
(108.29) \\
\end{array}$ & $\begin{array}{c}127.36 \\
(113.44) \\
\end{array}$ & $\begin{array}{c}160.09 \\
(125.34)\end{array}$ & 146.73 & $\begin{array}{c}149.25 \\
(149.15)\end{array}$ & $\begin{array}{c}169.07 \\
(152.51) \\
\end{array}$ & $\begin{array}{c}210.92 \\
(164.78) \\
\end{array}$ & 208.92 & $\begin{array}{c}210.67 \\
(209.54)\end{array}$ & $\begin{array}{c}234.00 \\
(213.85)\end{array}$ & $\begin{array}{c}275.59 \\
(229.53) \\
\end{array}$ \\
\hline$E A R L_{1,2}$ & 5.85 & $\begin{array}{c}6.05 \\
(5.91) \\
\end{array}$ & $\begin{array}{c}7.08 \\
(6.15) \\
\end{array}$ & $\begin{array}{c}9.98 \\
(6.88) \\
\end{array}$ & 6.31 & $\begin{array}{c}6.60 \\
(6.37) \\
\end{array}$ & $\begin{array}{c}8.40 \\
(6.785) \\
\end{array}$ & $\begin{array}{l}14.34 \\
(8.05) \\
\end{array}$ & 15.67 & $\begin{array}{c}16.57 \\
(15.84) \\
\end{array}$ & $\begin{array}{c}22.43 \\
(17.26) \\
\end{array}$ & $\begin{array}{c}39.29 \\
(21.03) \\
\end{array}$ \\
\hline$E A R L_{2,3}$ & 2.73 & $\begin{array}{c}2.81 \\
(2.75) \\
\end{array}$ & $\begin{array}{c}3.21 \\
(2.85) \\
\end{array}$ & $\begin{array}{c}4.19 \\
(3.14) \\
\end{array}$ & 2.18 & $\begin{array}{c}2.25 \\
(2.19) \\
\end{array}$ & $\begin{array}{c}2.64 \\
(2.29) \\
\end{array}$ & $\begin{array}{c}3.78 \\
(2.55) \\
\end{array}$ & 3.03 & $\begin{array}{c}3.20 \\
(3.07) \\
\end{array}$ & $\begin{array}{c}4.18 \\
(3.29) \\
\end{array}$ & $\begin{array}{c}7.51 \\
(3.95) \\
\end{array}$ \\
\hline$E A R L_{0,2}$ & 57.80 & $\begin{array}{c}58.84 \\
(57.10) \\
\end{array}$ & $\begin{array}{c}67.22 \\
(59.80) \\
\end{array}$ & $\begin{array}{c}85.03 \\
(66.08) \\
\end{array}$ & 76.52 & $\begin{array}{c}77.92 \\
(77.76) \\
\end{array}$ & $\begin{array}{c}88.73 \\
(79.65) \\
\end{array}$ & $\begin{array}{c}112.63 \\
(86.42) \\
\end{array}$ & 112.30 & $\begin{array}{c}113.62 \\
(112.69) \\
\end{array}$ & $\begin{array}{c}128.22 \\
(115.56) \\
\end{array}$ & $\begin{array}{c}157.44 \\
(125.28) \\
\end{array}$ \\
\hline$E A R L_{1,3}$ & 4.29 & $\begin{array}{c}4.43 \\
(4.33) \\
\end{array}$ & $\begin{array}{c}5.14 \\
(4.50) \\
\end{array}$ & $\begin{array}{c}7.09 \\
(4.97) \\
\end{array}$ & 4.24 & $\begin{array}{c}4.43 \\
(4.28) \\
\end{array}$ & $\begin{array}{c}5.52 \\
(4.54) \\
\end{array}$ & $\begin{array}{c}9.06 \\
(5.30) \\
\end{array}$ & 9.35 & $\begin{array}{c}9.89 \\
(9.45) \\
\end{array}$ & $\begin{array}{c}13.31 \\
(10.28)\end{array}$ & $\begin{array}{c}23.40 \\
(12.49) \\
\end{array}$ \\
\hline \multirow[t]{2}{*}{$E A R L_{0,3}$} & 39.44 & $\begin{array}{c}40.16 \\
(38.98) \\
\end{array}$ & $\begin{array}{c}45.88 \\
(40.81) \\
\end{array}$ & $\begin{array}{c}58.09 \\
(45.09) \\
\end{array}$ & 51.74 & $\begin{array}{c}52.70 \\
(52.57) \\
\end{array}$ & $\begin{array}{c}60.04 \\
(53.86) \\
\end{array}$ & $\begin{array}{c}76.35 \\
(58.46) \\
\end{array}$ & 75.87 & $\begin{array}{c}76.81 \\
(76.15) \\
\end{array}$ & $\begin{array}{c}86.87 \\
(78.14) \\
\end{array}$ & $\begin{array}{r}107.46 \\
(84.84) \\
\end{array}$ \\
\hline & \multicolumn{4}{|c|}{$L^{*}=3.4733$} & \multicolumn{4}{|c|}{$L^{*}=3.2957$} & \multicolumn{4}{|c|}{$L^{*}=3.2253$} \\
\hline
\end{tabular}


Table 2: The $A R L$ and $E A R L$ profiles of the HWMA $\bar{X}^{*}$ scheme in Case $\mathrm{U}$ when $(m, n)=(100,5), C \in$ $\{0,1,2,3\}, D \in\{0,1,2,3\}, \mu_{0}=1$ and $(\lambda, L)=(0.1,3.320)$ for $r=1$ (and $r=4$ in parentheses)

\begin{tabular}{|c|c|c|c|c|c|c|c|c|}
\hline \multirow[b]{2}{*}{ Shift } & \multicolumn{4}{|c|}{$D=0$} & \multicolumn{4}{|c|}{$C=0$} \\
\hline & $C=0$ & $C=1$ & $C=2$ & $C=3$ & $D=0$ & $D=1$ & $D=2$ & $D=3$ \\
\hline 0.00 & 498.45 & $\begin{array}{c}500.10 \\
(501.16)\end{array}$ & $\begin{array}{c}497.37 \\
(499.49)\end{array}$ & $\begin{array}{c}500.00 \\
(500.22)\end{array}$ & 498.14 & $\begin{array}{c}497.07 \\
(504.52)\end{array}$ & $\begin{array}{c}498.96 \\
(503.58)\end{array}$ & $\begin{array}{c}502.74 \\
(498.23)\end{array}$ \\
\hline 0.25 & 138.98 & $\begin{array}{c}242.28 \\
(171.32) \\
\end{array}$ & $\begin{array}{c}297.41 \\
(195.76) \\
\end{array}$ & $\begin{array}{c}336.46 \\
(220.06) \\
\end{array}$ & 135.46 & $\begin{array}{c}232.62 \\
(163.09) \\
\end{array}$ & $\begin{array}{c}292.43 \\
(190.88) \\
\end{array}$ & $\begin{array}{c}331.67 \\
(216.05) \\
\end{array}$ \\
\hline 0.5 & 35.75 & $\begin{array}{c}69.70 \\
(43.71) \\
\end{array}$ & $\begin{array}{r}103.98 \\
(51.94) \\
\end{array}$ & $\begin{array}{r}140.82 \\
(60.49) \\
\end{array}$ & 35.07 & $\begin{array}{c}66.17 \\
(42.11) \\
\end{array}$ & $\begin{array}{c}99.34 \\
(51.07) \\
\end{array}$ & $\begin{array}{r}135.18 \\
(58.84) \\
\end{array}$ \\
\hline 0.75 & 17.44 & $\begin{array}{c}32.15 \\
(21.17) \\
\end{array}$ & $\begin{array}{c}46.79 \\
(24.77) \\
\end{array}$ & $\begin{array}{c}62.07 \\
(28.26) \\
\end{array}$ & 16.96 & $\begin{array}{c}31.50 \\
(20.59) \\
\end{array}$ & $\begin{array}{c}44.85 \\
(24.19) \\
\end{array}$ & $\begin{array}{r}59.77 \\
(27.80) \\
\end{array}$ \\
\hline 1.00 & 10.57 & $\begin{array}{c}19.28 \\
(12.83) \\
\end{array}$ & $\begin{array}{c}27.42 \\
(14.97) \\
\end{array}$ & $\begin{array}{c}35.68 \\
(17.09) \\
\end{array}$ & 10.32 & $\begin{array}{c}18.64 \\
(12.52) \\
\end{array}$ & $\begin{array}{c}26.88 \\
(14.52)\end{array}$ & $\begin{array}{c}34.53 \\
(16.72)\end{array}$ \\
\hline 1.25 & 7.31 & $\begin{array}{l}13.09 \\
(8.76) \\
\end{array}$ & $\begin{array}{c}18.63 \\
(10.21) \\
\end{array}$ & $\begin{array}{c}24.00 \\
(11.71) \\
\end{array}$ & 7.04 & $\begin{array}{l}12.79 \\
(8.51) \\
\end{array}$ & $\begin{array}{l}18.04 \\
(9.99) \\
\end{array}$ & $\begin{array}{c}23.26 \\
(11.29) \\
\end{array}$ \\
\hline 1.5 & 5.49 & $\begin{array}{c}9.61 \\
(6.51)\end{array}$ & $\begin{array}{l}13.56 \\
(7.57)\end{array}$ & $\begin{array}{l}17.45 \\
(8.59)\end{array}$ & 5.26 & $\begin{array}{c}9.23 \\
(6.30) \\
\end{array}$ & $\begin{array}{l}13.22 \\
(7.27)\end{array}$ & $\begin{array}{l}16.99 \\
(8.31)\end{array}$ \\
\hline 1.75 & 4.38 & $\begin{array}{c}7.42 \\
(5.16) \\
\end{array}$ & $\begin{array}{l}10.44 \\
(5.90) \\
\end{array}$ & $\begin{array}{l}13.32 \\
(6.69) \\
\end{array}$ & 4.14 & $\begin{array}{c}7.10 \\
(4.92) \\
\end{array}$ & $\begin{array}{l}10.11 \\
(5.3) \\
\end{array}$ & $\begin{array}{l}12.94 \\
(6.45) \\
\end{array}$ \\
\hline 2.00 & 3.62 & $\begin{array}{c}6.01 \\
(4.24) \\
\end{array}$ & $\begin{array}{r}8.28 \\
(4.83) \\
\end{array}$ & $\begin{array}{l}10.55 \\
(5.43) \\
\end{array}$ & 3.41 & $\begin{array}{c}5.77 \\
(4.00) \\
\end{array}$ & $\begin{array}{c}8.01 \\
(4.60) \\
\end{array}$ & $\begin{array}{l}10.41 \\
(5.19) \\
\end{array}$ \\
\hline 2.25 & 3.10 & $\begin{array}{c}5.03 \\
(3.59) \\
\end{array}$ & $\begin{array}{r}6.94 \\
(4.08) \\
\end{array}$ & $\begin{array}{r}8.70 \\
(4.54) \\
\end{array}$ & 2.88 & $\begin{array}{c}4.77 \\
(3.37) \\
\end{array}$ & $\begin{array}{c}6.60 \\
(3.84) \\
\end{array}$ & $\begin{array}{c}8.39 \\
(4.32) \\
\end{array}$ \\
\hline 2.5 & 2.67 & $\begin{array}{c}4.31 \\
(3.11)\end{array}$ & $\begin{array}{c}5.86 \\
(3.50)\end{array}$ & $\begin{array}{c}7.31 \\
(3.94)\end{array}$ & 2.50 & $\begin{array}{c}4.06 \\
(2.90)\end{array}$ & $\begin{array}{c}5.57 \\
(3.30)\end{array}$ & $\begin{array}{c}7.08 \\
(3.71)\end{array}$ \\
\hline 2.75 & 2.33 & $\begin{array}{c}3.76 \\
(2.73) \\
\end{array}$ & $\begin{array}{c}5.05 \\
(3.10) \\
\end{array}$ & $\begin{array}{c}6.30 \\
(3.44) \\
\end{array}$ & 2.20 & $\begin{array}{c}3.54 \\
(2.56) \\
\end{array}$ & $\begin{array}{c}4.80 \\
(2.90) \\
\end{array}$ & $\begin{array}{c}6.03 \\
(3.22) \\
\end{array}$ \\
\hline 3.00 & 2.04 & $\begin{array}{c}3.34 \\
(2.42) \\
\end{array}$ & $\begin{array}{c}4.44 \\
(2.75) \\
\end{array}$ & $\begin{array}{c}5.51 \\
(3.06) \\
\end{array}$ & 1.97 & $\begin{array}{c}3.11 \\
(2.29) \\
\end{array}$ & $\begin{array}{c}4.21 \\
(2.59) \\
\end{array}$ & $\begin{array}{c}5.24 \\
(2.84) \\
\end{array}$ \\
\hline$E A R L_{0,1}$ & 50.68 & $\begin{array}{c}90.85 \\
(62.26)\end{array}$ & $\begin{array}{r}118.90 \\
(71.86) \\
\end{array}$ & $\begin{array}{r}143.76 \\
(81.47) \\
\end{array}$ & 49.45 & $\begin{array}{c}87.23 \\
(59.58) \\
\end{array}$ & $\begin{array}{c}115.88 \\
(70.17)\end{array}$ & $\begin{array}{r}140.29 \\
(79.85)\end{array}$ \\
\hline$E A R L_{1,2}$ & 5.20 & $\begin{array}{c}9.03 \\
(6.16)\end{array}$ & $\begin{array}{l}12.73 \\
(7.13)\end{array}$ & $\begin{array}{l}16.33 \\
(8.10)\end{array}$ & 4.96 & $\begin{array}{c}8.72 \\
(5.93) \\
\end{array}$ & $\begin{array}{l}12.35 \\
(6.87)\end{array}$ & $\begin{array}{l}15.90 \\
(7.81)\end{array}$ \\
\hline$E A R L_{2,3}$ & 2.54 & $\begin{array}{c}4.11 \\
(2.96) \\
\end{array}$ & $\begin{array}{c}5.57 \\
(3.36) \\
\end{array}$ & $\begin{array}{c}6.95 \\
(3.75) \\
\end{array}$ & 2.39 & $\begin{array}{c}3.87 \\
(2.78) \\
\end{array}$ & $\begin{array}{c}5.30 \\
(3.16) \\
\end{array}$ & $\begin{array}{c}6.69 \\
(3.52) \\
\end{array}$ \\
\hline$E A R L_{0,2}$ & 27.94 & $\begin{array}{c}49.94 \\
(34.21) \\
\end{array}$ & $\begin{array}{c}65.82 \\
(39.49) \\
\end{array}$ & $\begin{array}{c}80.04 \\
(44.79) \\
\end{array}$ & 27.21 & $\begin{array}{c}47.98 \\
(32.76) \\
\end{array}$ & $\begin{array}{c}64.11 \\
(38.52) \\
\end{array}$ & $\begin{array}{c}78.09 \\
(43.83) \\
\end{array}$ \\
\hline$E A R L_{1,3}$ & 3.87 & $\begin{array}{c}6.57 \\
(4.56) \\
\end{array}$ & $\begin{array}{c}9.15 \\
(5.24) \\
\end{array}$ & $\begin{array}{l}11.64 \\
(5.92) \\
\end{array}$ & 3.68 & $\begin{array}{c}6.30 \\
(4.36) \\
\end{array}$ & $\begin{array}{c}8.82 \\
(5.02) \\
\end{array}$ & $\begin{array}{l}11.29 \\
(5.67) \\
\end{array}$ \\
\hline$E A R L_{0,3}$ & 19.47 & $\begin{array}{c}34.67 \\
(23.80)\end{array}$ & $\begin{array}{c}45.73 \\
(27.44) \\
\end{array}$ & $\begin{array}{c}55.68 \\
(31.11)\end{array}$ & 18.93 & $\begin{array}{c}33.28 \\
(22.76)\end{array}$ & $\begin{array}{c}44.51 \\
(26.73)\end{array}$ & $\begin{array}{c}54.29 \\
(30.40)\end{array}$ \\
\hline
\end{tabular}


Table 3: $A R L$ profiles for the HWMA $\bar{X}^{*}$ monitoring scheme for different continuous distributions when $\lambda=0.1$ for a nominal $A R L_{0}$ value of 500

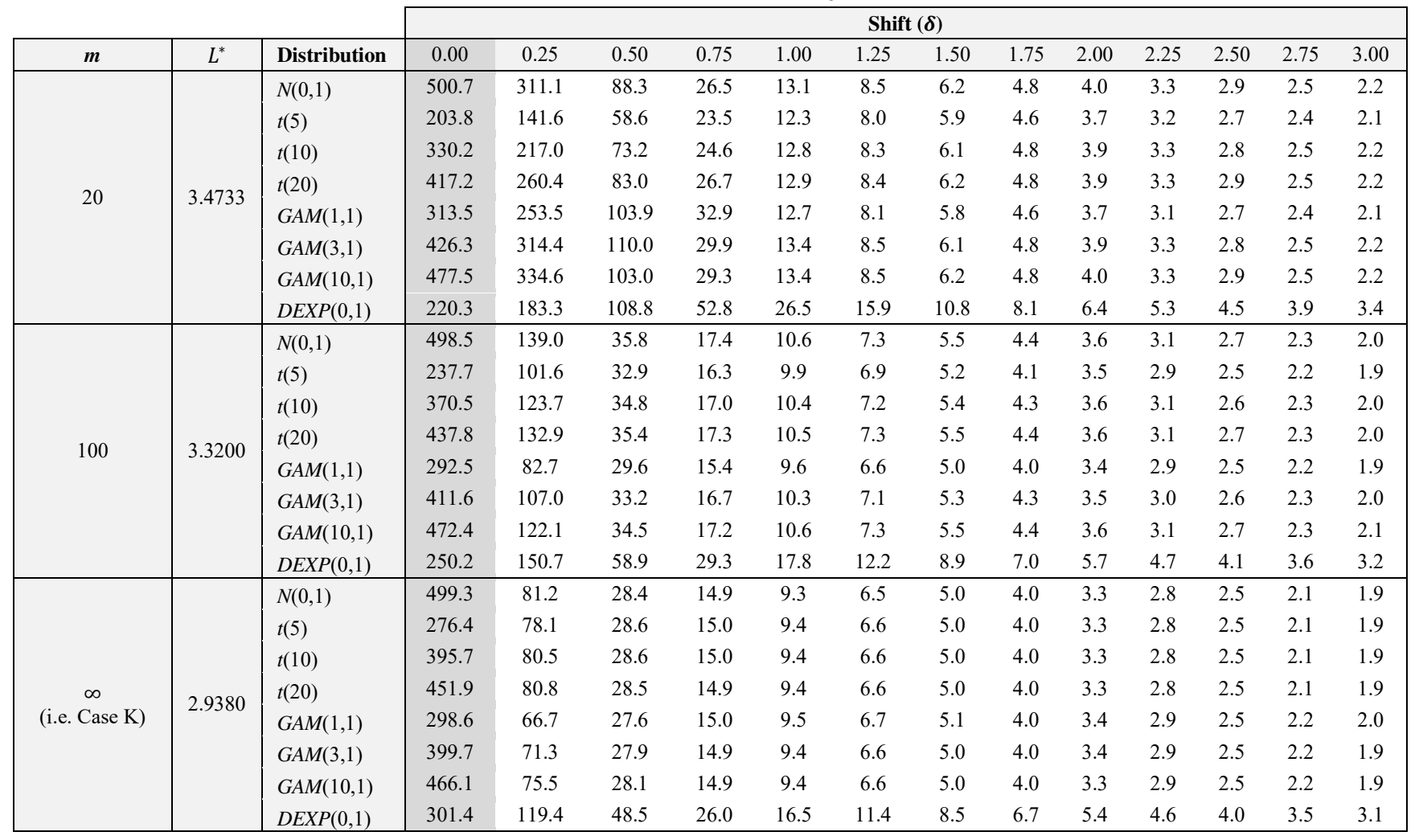


Table 4: Performance comparison of the HWMA $\bar{X}^{*}$ scheme with the EWMA $\bar{X}^{*}$, CUSUM $\bar{X}^{*}$ and GWMA $\bar{X}^{*}$ schemes in Case U when $\lambda=0.1$, $m=100, n=5, \gamma \in\{0,0.2,0.5,0.9\}$ for a nominal $A R L_{0}$ value of 500

\begin{tabular}{|c|c|c|c|c|c|c|c|c|c|c|c|c|c|c|c|c|}
\hline \multirow{3}{*}{ Shift } & \multicolumn{4}{|c|}{ CUSUM $\bar{X}^{*}$ scheme } & \multicolumn{4}{|c|}{ EWMA $\bar{X}^{*}$ scheme } & \multicolumn{4}{|c|}{ GWMA $\bar{X}^{*}$ scheme } & \multicolumn{4}{|c|}{ HWMA $\bar{X}^{*}$ scheme } \\
\hline & \multicolumn{4}{|c|}{$k_{C}=0.125$ and $H_{C}=6.7289$} & \multicolumn{4}{|c|}{$L_{E}=2.9384$ and $\lambda_{E}=0.1$} & \multicolumn{4}{|c|}{$L_{G}=3.3356, \alpha=0.5$ and $q=0.9$} & \multicolumn{4}{|c|}{$L^{*}=3.3200$ and $\lambda=0.1$} \\
\hline & $\gamma=0$ & $\gamma=0.2$ & $\gamma=0.5$ & $\gamma=0.9$ & $\gamma=0$ & $\gamma=0.2$ & $\gamma=0.5$ & $\gamma=0.9$ & $\gamma=0$ & $\gamma=0.2$ & $\gamma=0.5$ & $\gamma=0.9$ & $\gamma=0$ & $\gamma=0.2$ & $\gamma=0.5$ & $\gamma=0.9$ \\
\hline 0.00 & 503.24 & $\begin{array}{r}499.77 \\
(501.90) \\
\end{array}$ & $\begin{array}{r}498.07 \\
(501.77) \\
\end{array}$ & $\begin{array}{r}502.76 \\
(500.25) \\
\end{array}$ & 495.71 & $\begin{array}{c}492.42 \\
(500.87) \\
\end{array}$ & $\begin{array}{r}501.15 \\
(499.63) \\
\end{array}$ & $\begin{array}{r}495.15 \\
(499.04) \\
\end{array}$ & 498.96 & $\begin{array}{r}499.63 \\
(508.96) \\
\end{array}$ & $\begin{array}{c}494.92 \\
(499.94) \\
\end{array}$ & $\begin{array}{r}497.89 \\
(502.55) \\
\end{array}$ & 498.45 & $\begin{array}{c}501.17 \\
(498.72)\end{array}$ & $\begin{array}{c}501.76 \\
(500.13) \\
\end{array}$ & $\begin{array}{r}500.92 \\
(499.21) \\
\end{array}$ \\
\hline 0.25 & 222.43 & $\begin{array}{c}239.91 \\
(107.15)\end{array}$ & $\begin{array}{c}259.33 \\
(227.72) \\
\end{array}$ & $\begin{array}{c}290.97 \\
(268.37)\end{array}$ & 171.74 & $\begin{array}{c}174.86 \\
(171.26)\end{array}$ & $\begin{array}{c}204.30 \\
(178.49)\end{array}$ & $\begin{array}{c}264.51 \\
(197.76)\end{array}$ & 149.03 & $\begin{array}{c}150.57 \\
(147.11)\end{array}$ & $\begin{array}{c}177.97 \\
(156.37)\end{array}$ & $\begin{array}{c}229.92 \\
(171.15)\end{array}$ & 138.98 & $\begin{array}{c}146.10 \\
(142.44)\end{array}$ & $\begin{array}{c}169.31 \\
(145.79)\end{array}$ & $\begin{array}{c}225.00 \\
(162.78)\end{array}$ \\
\hline 0.50 & 46.79 & $\begin{array}{c}55.28 \\
(49.55)\end{array}$ & $\begin{array}{c}61.70 \\
(54.29)\end{array}$ & $\begin{array}{c}81.21 \\
(63.23)\end{array}$ & 37.36 & $\begin{array}{c}38.99 \\
(38.09)\end{array}$ & $\begin{array}{c}48.42 \\
(40.03)\end{array}$ & $\begin{array}{c}74.58 \\
(45.99)\end{array}$ & 39.17 & $\begin{array}{c}40.53 \\
(39.27) \\
\end{array}$ & $\begin{array}{c}47.97 \\
(41.37)\end{array}$ & $\begin{array}{c}68.96 \\
(45.83) \\
\end{array}$ & 35.75 & $\begin{array}{c}36.88 \\
(35.86)\end{array}$ & $\begin{array}{c}43.85 \\
(37.73)\end{array}$ & $\begin{array}{c}63.22 \\
(42.68)\end{array}$ \\
\hline 0.75 & 18.64 & $\begin{array}{c}29.42 \\
(14.79)\end{array}$ & $\begin{array}{c}30.59 \\
(20.07)\end{array}$ & $\begin{array}{c}39.13 \\
(29.04)\end{array}$ & 15.64 & $\begin{array}{l}16.364 \\
(15.98)\end{array}$ & $\begin{array}{c}19.85 \\
(16.73)\end{array}$ & $\begin{array}{c}29.24 \\
(19.06)\end{array}$ & 18.79 & $\begin{array}{c}19.48 \\
(19.14)\end{array}$ & $\begin{array}{c}23.01 \\
(19.79)\end{array}$ & $\begin{array}{c}32.03 \\
(22.11)\end{array}$ & 17.44 & $\begin{array}{c}18.07 \\
(17.58)\end{array}$ & $\begin{array}{c}21.21 \\
(18.31)\end{array}$ & $\begin{array}{c}29.4 \\
(20.40)\end{array}$ \\
\hline 1.00 & 18.56 & $\begin{array}{c}21.68 \\
(12.22)\end{array}$ & $\begin{array}{c}29.04 \\
(14.99)\end{array}$ & $\begin{array}{c}37.33 \\
(18.08)\end{array}$ & 9.11 & $\begin{array}{c}9.44 \\
(9.20)\end{array}$ & $\begin{array}{l}11.26 \\
(9.67)\end{array}$ & $\begin{array}{c}16.06 \\
(10.78)\end{array}$ & 11.39 & $\begin{array}{c}11.99 \\
(11.51)\end{array}$ & $\begin{array}{c}13.87 \\
(12.01)\end{array}$ & $\begin{array}{c}19.22 \\
(13.39)\end{array}$ & 10.57 & $\begin{array}{c}10.95 \\
(10.72)\end{array}$ & $\begin{array}{c}12.78 \\
(11.14)\end{array}$ & $\begin{array}{c}17.68 \\
(12.41)\end{array}$ \\
\hline 1.25 & 13.18 & $\begin{array}{c}14.14 \\
(11.14) \\
\end{array}$ & $\begin{array}{c}19.43 \\
(12.35) \\
\end{array}$ & $\begin{array}{c}23.12 \\
(14.02) \\
\end{array}$ & 6.15 & $\begin{array}{c}6.35 \\
(6.17) \\
\end{array}$ & $\begin{array}{c}7.48 \\
(6.49)\end{array}$ & $\begin{array}{l}10.42 \\
(7.18) \\
\end{array}$ & 7.75 & $\begin{array}{c}8.02 \\
(7.79) \\
\end{array}$ & $\begin{array}{c}9.40 \\
(8.14)\end{array}$ & $\begin{array}{l}13.07 \\
(9.09) \\
\end{array}$ & 7.31 & $\begin{array}{c}7.58 \\
(7.39) \\
\end{array}$ & $\begin{array}{c}8.78 \\
(7.68)\end{array}$ & $\begin{array}{l}12.02 \\
(8.50)\end{array}$ \\
\hline 1.50 & 11.69 & $\begin{array}{l}11.94 \\
(8.57) \\
\end{array}$ & $\begin{array}{l}12.74 \\
(9.92)\end{array}$ & $\begin{array}{c}14.67 \\
(10.99) \\
\end{array}$ & 4.52 & $\begin{array}{c}4.64 \\
(4.54)\end{array}$ & $\begin{array}{c}5.43 \\
(4.74)\end{array}$ & $\begin{array}{r}7.45 \\
(5.27) \\
\end{array}$ & 5.62 & $\begin{array}{c}5.85 \\
(5.68) \\
\end{array}$ & $\begin{array}{c}6.85 \\
(5.94)\end{array}$ & $\begin{array}{c}9.076 \\
(6.61) \\
\end{array}$ & 5.49 & $\begin{array}{c}5.66 \\
(5.53) \\
\end{array}$ & $\begin{array}{c}6.53 \\
(5.76)\end{array}$ & $\begin{array}{c}8.85 \\
(6.37)\end{array}$ \\
\hline 1.75 & 9.11 & $\begin{array}{l}10.15 \\
(7.26)\end{array}$ & $\begin{array}{l}10.47 \\
(8.27)\end{array}$ & $\begin{array}{c}16.98 \\
(10.53)\end{array}$ & 3.50 & $\begin{array}{c}3.61 \\
(3.52)\end{array}$ & $\begin{array}{c}4.20 \\
(3.67)\end{array}$ & $\begin{array}{c}5.74 \\
(4.07)\end{array}$ & 4.31 & $\begin{array}{c}4.47 \\
(4.37)\end{array}$ & $\begin{array}{c}5.26 \\
(4.57)\end{array}$ & $\begin{array}{c}7.25 \\
(5.08) \\
\end{array}$ & 4.38 & $\begin{array}{c}4.49 \\
(4.40)\end{array}$ & $\begin{array}{c}5.17 \\
(4.57)\end{array}$ & $\begin{array}{c}6.90 \\
(5.01)\end{array}$ \\
\hline 2.00 & 8.66 & $\begin{array}{c}9.25 \\
(6.76) \\
\end{array}$ & $\begin{array}{c}9.94 \\
(8.05) \\
\end{array}$ & $\begin{array}{l}13.62 \\
(9.84) \\
\end{array}$ & 2.83 & $\begin{array}{c}2.91 \\
(2.85) \\
\end{array}$ & $\begin{array}{c}3.38 \\
(2.96) \\
\end{array}$ & $\begin{array}{c}4.55 \\
(3.27) \\
\end{array}$ & 3.44 & $\begin{array}{c}3.55 \\
(3.49) \\
\end{array}$ & $\begin{array}{c}4.18 \\
(3.63) \\
\end{array}$ & $\begin{array}{c}5.72 \\
(4.02) \\
\end{array}$ & 3.62 & $\begin{array}{c}3.73 \\
(3.64) \\
\end{array}$ & $\begin{array}{c}4.24 \\
(3.78) \\
\end{array}$ & $\begin{array}{c}5.58 \\
(4.12) \\
\end{array}$ \\
\hline 2.25 & 7.33 & $\begin{array}{c}7.83 \\
(6.30)\end{array}$ & $\begin{array}{c}8.87 \\
(7.11)\end{array}$ & $\begin{array}{c}9.38 \\
(8.51)\end{array}$ & 2.36 & $\begin{array}{c}2.44 \\
(2.39)\end{array}$ & $\begin{array}{c}2.81 \\
(2.48)\end{array}$ & $\begin{array}{c}3.77 \\
(2.72)\end{array}$ & 2.83 & $\begin{array}{c}2.93 \\
(2.84)\end{array}$ & $\begin{array}{c}3.42 \\
(2.97)\end{array}$ & $\begin{array}{c}4.70 \\
(3.30) \\
\end{array}$ & 3.10 & $\begin{array}{c}3.16 \\
(3.09)\end{array}$ & $\begin{array}{c}3.59 \\
(3.21)\end{array}$ & $\begin{array}{c}4.67 \\
(3.50)\end{array}$ \\
\hline 2.50 & 6.92 & $\begin{array}{c}7.25 \\
(5.61)\end{array}$ & $\begin{array}{c}7.56 \\
(6.90)\end{array}$ & $\begin{array}{c}9.18 \\
(8.03)\end{array}$ & 2.03 & $\begin{array}{c}2.08 \\
(2.04)\end{array}$ & $\begin{array}{c}2.39 \\
(2.12)\end{array}$ & $\begin{array}{c}3.19 \\
(2.31)\end{array}$ & 2.38 & $\begin{array}{c}2.45 \\
(2.39)\end{array}$ & $\begin{array}{c}2.85 \\
(2.49)\end{array}$ & $\begin{array}{c}3.87 \\
(2.76)\end{array}$ & 2.67 & $\begin{array}{c}2.75 \\
(2.69)\end{array}$ & $\begin{array}{c}3.11 \\
(2.78)\end{array}$ & $\begin{array}{c}4.02 \\
(3.02)\end{array}$ \\
\hline 2.75 & 5.82 & $\begin{array}{c}6.85 \\
(5.00) \\
\end{array}$ & $\begin{array}{c}7.26 \\
(6.15) \\
\end{array}$ & $\begin{array}{c}8.25 \\
(7.27) \\
\end{array}$ & 1.77 & $\begin{array}{c}1.82 \\
(1.79)\end{array}$ & $\begin{array}{c}2.07 \\
(1.84)\end{array}$ & $\begin{array}{c}2.74 \\
(2.02) \\
\end{array}$ & 2.03 & $\begin{array}{c}2.10 \\
(2.05)\end{array}$ & $\begin{array}{c}2.42 \\
(2.13)\end{array}$ & $\begin{array}{c}3.32 \\
(2.34)\end{array}$ & 2.33 & $\begin{array}{c}2.40 \\
(2.35) \\
\end{array}$ & $\begin{array}{c}2.73 \\
(2.44)\end{array}$ & $\begin{array}{c}3.51 \\
(2.65)\end{array}$ \\
\hline 3.00 & 5.70 & $\begin{array}{c}6.07 \\
(4.26)\end{array}$ & $\begin{array}{c}6.37 \\
(4.53)\end{array}$ & $\begin{array}{c}7.10 \\
(5.55)\end{array}$ & 1.58 & $\begin{array}{c}1.62 \\
(1.59)\end{array}$ & $\begin{array}{c}1.84 \\
(1.64)\end{array}$ & $\begin{array}{c}2.40 \\
(1.78)\end{array}$ & 1.77 & $\begin{array}{c}1.83 \\
(1.79)\end{array}$ & $\begin{array}{c}2.11 \\
(1.86)\end{array}$ & $\begin{array}{c}2.88 \\
(2.04)\end{array}$ & 2.04 & $\begin{array}{c}2.12 \\
(2.06)\end{array}$ & $\begin{array}{c}2.42 \\
(2.14)\end{array}$ & $\begin{array}{c}3.13 \\
(2.35)\end{array}$ \\
\hline$E A R L_{0,1}$ & 76.61 & $\begin{array}{c}86.57 \\
(45.93) \\
\end{array}$ & $\begin{array}{c}95.17 \\
(79.27) \\
\end{array}$ & $\begin{array}{l}112.16 \\
(94.68) \\
\end{array}$ & 58.46 & $\begin{array}{c}59.91 \\
(58.63) \\
\end{array}$ & $\begin{array}{c}70.96 \\
(61.23) \\
\end{array}$ & $\begin{array}{c}96.10 \\
(68.40) \\
\end{array}$ & 54.60 & $\begin{array}{c}55.64 \\
(54.26)\end{array}$ & $\begin{array}{c}65.70 \\
(57.38)\end{array}$ & $\begin{array}{c}87.53 \\
(63.12)\end{array}$ & 50.68 & $\begin{array}{c}53.00 \\
(51.65)\end{array}$ & $\begin{array}{c}61.79 \\
(53.24) \\
\end{array}$ & $\begin{array}{c}83.83 \\
(59.57) \\
\end{array}$ \\
\hline$E A R L_{1,2}$ & 10.66 & $\begin{array}{l}11.37 \\
(8.43)\end{array}$ & $\begin{array}{l}13.15 \\
(9.65) \\
\end{array}$ & $\begin{array}{c}17.10 \\
(11.15) \\
\end{array}$ & 4.25 & $\begin{array}{c}4.38 \\
(4.27)\end{array}$ & $\begin{array}{c}5.12 \\
(4.47) \\
\end{array}$ & $\begin{array}{c}7.04 \\
(4.95) \\
\end{array}$ & 5.28 & $\begin{array}{c}5.47 \\
(5.33) \\
\end{array}$ & $\begin{array}{c}6.43 \\
(5.57) \\
\end{array}$ & $\begin{array}{c}8.87 \\
(6.20) \\
\end{array}$ & 5.20 & $\begin{array}{c}5.37 \\
(5.24)\end{array}$ & $\begin{array}{c}6.18 \\
(5.45)\end{array}$ & $\begin{array}{c}8.34 \\
(6.00)\end{array}$ \\
\hline$E A R L_{2,3}$ & 6.44 & $\begin{array}{r}7.00 \\
(5.29) \\
\end{array}$ & $\begin{array}{r}7.52 \\
(6.17) \\
\end{array}$ & $\begin{array}{c}8.48 \\
(7.34) \\
\end{array}$ & 1.93 & $\begin{array}{l}1.99 \\
(1.95) \\
\end{array}$ & $\begin{array}{c}2.28 \\
(2.02)\end{array}$ & $\begin{array}{c}3.03 \\
(2.21) \\
\end{array}$ & 2.25 & $\begin{array}{c}2.33 \\
(2.27)\end{array}$ & $\begin{array}{c}2.70 \\
(2.36) \\
\end{array}$ & $\begin{array}{c}3.69 \\
(2.61) \\
\end{array}$ & 2.54 & $\begin{array}{c}2.61 \\
(2.55)\end{array}$ & $\begin{array}{c}2.96 \\
(2.64) \\
\end{array}$ & $\begin{array}{c}3.83 \\
(2.88)\end{array}$ \\
\hline$E A R L_{0,2}$ & 43.63 & $\begin{array}{c}48.97 \\
(27.18)\end{array}$ & $\begin{array}{c}54.16 \\
(44.46)\end{array}$ & $\begin{array}{c}64.63 \\
(53.01)\end{array}$ & 31.35 & $\begin{array}{c}32.15 \\
(31.45)\end{array}$ & $\begin{array}{c}38.04 \\
(32.85)\end{array}$ & $\begin{array}{c}51.57 \\
(36.67)\end{array}$ & 29.94 & $\begin{array}{c}30.56 \\
(29.80) \\
\end{array}$ & $\begin{array}{c}36.06 \\
(31.48) \\
\end{array}$ & $\begin{array}{c}48.20 \\
(34.66) \\
\end{array}$ & 27.94 & $\begin{array}{c}29.18 \\
(28.45)\end{array}$ & $\begin{array}{c}33.98 \\
(29.35)\end{array}$ & $\begin{array}{c}46.08 \\
(32.78)\end{array}$ \\
\hline$E A R L_{1,3}$ & 8.55 & $\begin{array}{c}9.19 \\
(6.86)\end{array}$ & $\begin{array}{l}10.33 \\
(7.91)\end{array}$ & $\begin{array}{l}12.79 \\
(9.34)\end{array}$ & 3.09 & $\begin{array}{c}3.18 \\
(3.11)\end{array}$ & $\begin{array}{c}3.70 \\
(3.24)\end{array}$ & $\begin{array}{c}5.03 \\
(4.58)\end{array}$ & 3.77 & $\begin{array}{c}3.90 \\
(3.80)\end{array}$ & $\begin{array}{c}4.56 \\
(3.97)\end{array}$ & $\begin{array}{c}6.28 \\
(4.40) \\
\end{array}$ & 3.87 & $\begin{array}{c}3.99 \\
(3.89)\end{array}$ & $\begin{array}{c}4.57 \\
(4.05)\end{array}$ & $\begin{array}{c}6.09 \\
(4.44)\end{array}$ \\
\hline$E A R L_{0,3}$ & 31.24 & $\begin{array}{c}34.98 \\
(19.88)\end{array}$ & $\begin{array}{c}38.61 \\
(31.70) \\
\end{array}$ & $\begin{array}{c}45.91 \\
(37.79)\end{array}$ & 21.55 & $\begin{array}{c}22.09 \\
(21.62) \\
\end{array}$ & $\begin{array}{c}26.12 \\
(22.57) \\
\end{array}$ & $\begin{array}{c}35.39 \\
(25.18) \\
\end{array}$ & 20.71 & $\begin{array}{c}21.15 \\
(20.62) \\
\end{array}$ & $\begin{array}{c}24.94 \\
(21.77) \\
\end{array}$ & $\begin{array}{c}33.37 \\
(23.98) \\
\end{array}$ & 19.47 & $\begin{array}{c}20.32 \\
(19.81)\end{array}$ & $\begin{array}{c}23.64 \\
(20.44)\end{array}$ & $\begin{array}{c}32.00 \\
(22.82)\end{array}$ \\
\hline
\end{tabular}


Table 5: Illustration of the implementation of the HWMA $\bar{X}^{*}$ scheme using the yogurt cup filling data

\begin{tabular}{|c|c|c|c|c|c|c|c|c|c|c|c|c|c|c|c|c|}
\hline$t$ & $X_{t, 1,1}^{*}$ & $X_{t, 1,2}^{*}$ & $X_{t, 2,1}^{*}$ & $X_{t, 2,2}^{*}$ & $X_{t, 3,1}^{*}$ & $X_{t, 3,2}^{*}$ & $X_{t, 4,1}^{*}$ & $X_{t, 4,2}^{*}$ & $X_{t, 5,1}^{*}$ & $X_{t, 5,2}^{*}$ & $\bar{X}_{t}^{*}$ & $\overline{\bar{X}}_{t-1}^{*}$ & $H_{t}^{*}$ & $L C L_{t}$ & $U C L_{t}$ & Signal \\
\hline 1 & 124.9 & 125.9 & 125.2 & 124.6 & 124.8 & 124.8 & 125.9 & 124.8 & 124.1 & 124.4 & 124.94 & 124.90 & 124.90 & 124.78 & 125.02 & No \\
\hline 2 & 124.9 & 125.5 & 124.1 & 125.2 & 125.0 & 125.2 & 125.0 & 123.9 & 125.2 & 125.6 & 124.96 & 124.94 & 124.94 & 123.85 & 125.95 & No \\
\hline 3 & 125.1 & 125.2 & 125.4 & 122.9 & 125.4 & 125.1 & 124.8 & 125.3 & 122.4 & 125.4 & 124.70 & 124.95 & 124.93 & 124.16 & 125.65 & No \\
\hline 4 & 126.1 & 124.6 & 125.7 & 126.4 & 124.9 & 125.9 & 124.8 & 125.5 & 126.5 & 125.7 & 125.61 & 124.87 & 124.94 & 124.29 & 125.51 & No \\
\hline 5 & 125.8 & 122.6 & 124.1 & 126.1 & 124.9 & 125.7 & 122.6 & 123.5 & 126.3 & 125.0 & 124.66 & 125.05 & 125.01 & 124.37 & 125.43 & No \\
\hline 6 & 125.0 & 125.5 & 124.8 & 124.9 & 124.8 & 125.2 & 124.8 & 125.0 & 124.8 & 124.2 & 124.90 & 124.97 & 124.97 & 124.42 & 125.38 & No \\
\hline 7 & 124.2 & 125.8 & 125.4 & 126.4 & 125.1 & 124.6 & 125.3 & 125.5 & 126.2 & 125.2 & 125.37 & 124.96 & 125.00 & 124.46 & 125.34 & No \\
\hline 8 & 124.9 & 123.8 & 125.1 & 124.0 & 124.4 & 124.9 & 123.2 & 125.3 & 124.5 & 124.2 & 124.43 & 125.02 & 124.96 & 124.49 & 125.31 & No \\
\hline 9 & 125.9 & 124.4 & 126.3 & 124.9 & 125.2 & 125.8 & 124.8 & 125.7 & 125.2 & 125.1 & 125.33 & 124.95 & 124.98 & 124.51 & 125.29 & No \\
\hline 10 & 124.2 & 126.2 & 125.6 & 124.4 & 124.1 & 124.3 & 125.5 & 125.0 & 124.4 & 124.3 & 124.80 & 124.99 & 124.97 & 124.53 & 125.27 & No \\
\hline 11 & 123.7 & 123.4 & 124.7 & 123.1 & 123.1 & 123.6 & 123.3 & 124.8 & 123.1 & 122.8 & 123.56 & 124.97 & 124.83 & 124.55 & 125.25 & No \\
\hline 12 & 124.0 & 122.6 & 123.6 & 124.4 & 123.6 & 124.1 & 122.4 & 123.6 & 124.5 & 123.1 & 123.59 & 124.84 & 124.72 & 124.57 & 125.24 & No \\
\hline 13 & 122.0 & 123.9 & 123.7 & 124.3 & 121.9 & 122.5 & 124.0 & 124.1 & 124.4 & 122.9 & 123.37 & 124.74 & 124.60 & 124.58 & 125.22 & No \\
\hline 14 & 122.4 & 122.8 & 123.7 & 123.7 & 122.8 & 123.0 & 123.1 & 124.2 & 124.1 & 123.1 & 123.29 & 124.63 & 124.50 & 124.59 & 125.21 & Yes \\
\hline 15 & 123.9 & 124.1 & 123.4 & 123.1 & 124.5 & 123.6 & 124.5 & 122.9 & 123.1 & 125.1 & 123.82 & 124.54 & 124.46 & 124.60 & 125.20 & Yes \\
\hline 16 & 121.9 & 123.4 & 123.5 & 125.3 & 123.3 & 122.3 & 123.3 & 123.3 & 125.5 & 123.6 & 123.54 & 124.49 & 124.39 & 124.61 & 125.19 & Yes \\
\hline 17 & 123.3 & 123.6 & 124.2 & 123.4 & 123.5 & 122.9 & 123.5 & 123.8 & 123.6 & 123.4 & 123.52 & 124.43 & 124.34 & 124.62 & 125.19 & Yes \\
\hline 18 & 122.0 & 123.6 & 124.7 & 122.6 & 124.5 & 122.2 & 123.4 & 125.0 & 122.5 & 123.9 & 123.44 & 124.38 & 124.28 & 124.62 & 125.18 & Yes \\
\hline 19 & 124.0 & 123.1 & 123.9 & 122.6 & 124.2 & 123.9 & 123.4 & 124.5 & 122.8 & 123.5 & 123.59 & 124.32 & 124.25 & 124.63 & 125.17 & Yes \\
\hline 20 & 125.5 & 122.2 & 123.2 & 123.2 & 123.2 & 124.9 & 122.3 & 123.2 & 123.3 & 123.2 & 123.42 & 124.29 & 124.20 & 124.64 & 125.17 & Yes \\
\hline
\end{tabular}




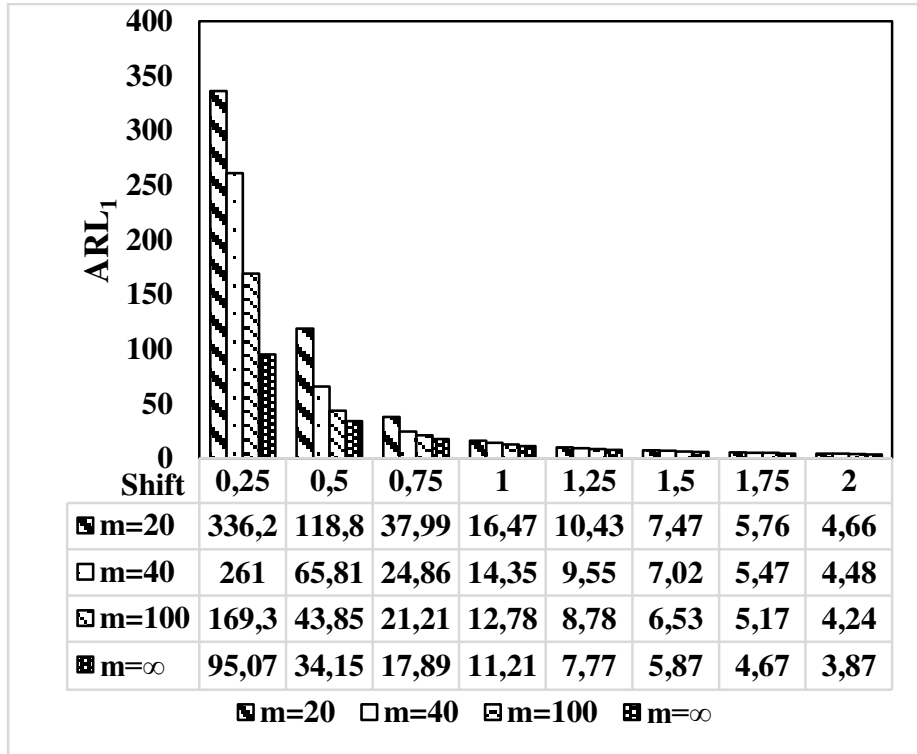

$r=1$

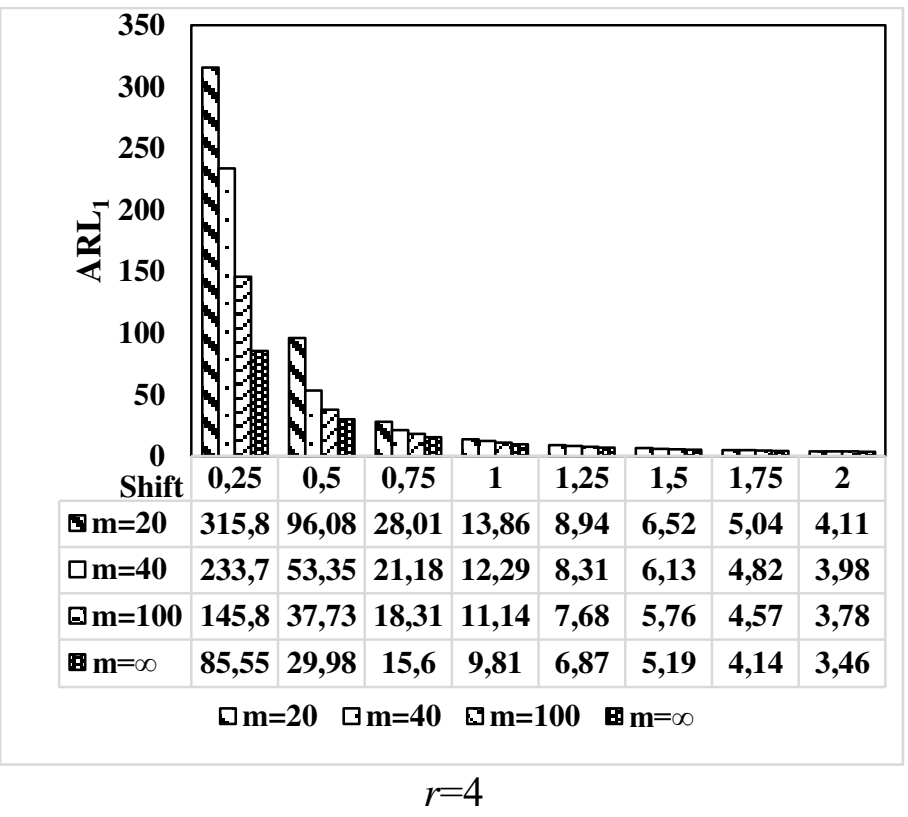

Figure 1: $A R L_{1}$ profiles for the HWMA $\bar{X}^{*}$ scheme when $\lambda=0.1, \gamma=0.5$ and $m \in\{20,40,100, \infty\}$



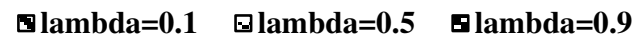

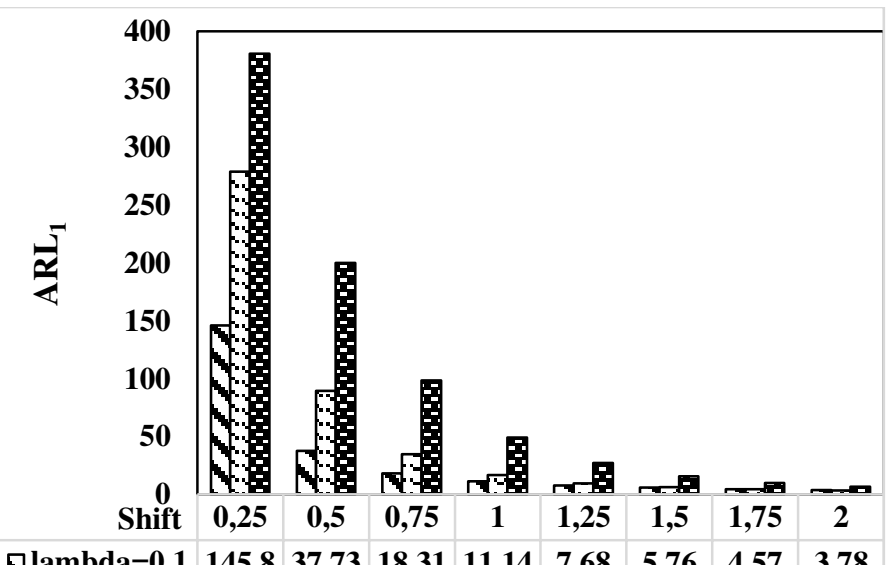

\begin{tabular}{|l|l|l|l|l|l|l|l|l|l|}
\hline vlambda=0.1 & 145,8 & 37,73 & 18,31 & 11,14 & 7,68 & 5,76 & 4,57 & 3,78 \\
\hline
\end{tabular}

\begin{tabular}{|l|l|l|l|l|l|l|l|l|l|}
\hline Qlambda=0.5 & 278,8 & 89,50 & 34,53 & 16,66 & 9,68 & 6,36 & 4,53 & 3,49 \\
\hline
\end{tabular}

\begin{tabular}{|l|l|l|l|l|l|l|l|l|l|}
\hline alambda=0.9 & 380,8 & 199,9 & 98,42 & 49,25 & 27,11 & 15,64 & 9,75 & 6,45 \\
\hline
\end{tabular}

$\square$ lambda $=0.1 \quad \square$ lambda $=0.5 \quad$ Ilambda $=0.9$

$$
r=1
$$$$
r=4
$$

Figure 2: $A R L_{1}$ profiles for the HWMA $\bar{X}^{*}$ scheme when $m=100, \gamma=0.5$ and $\lambda \in\{0.1,0.5,0.9\}$ 


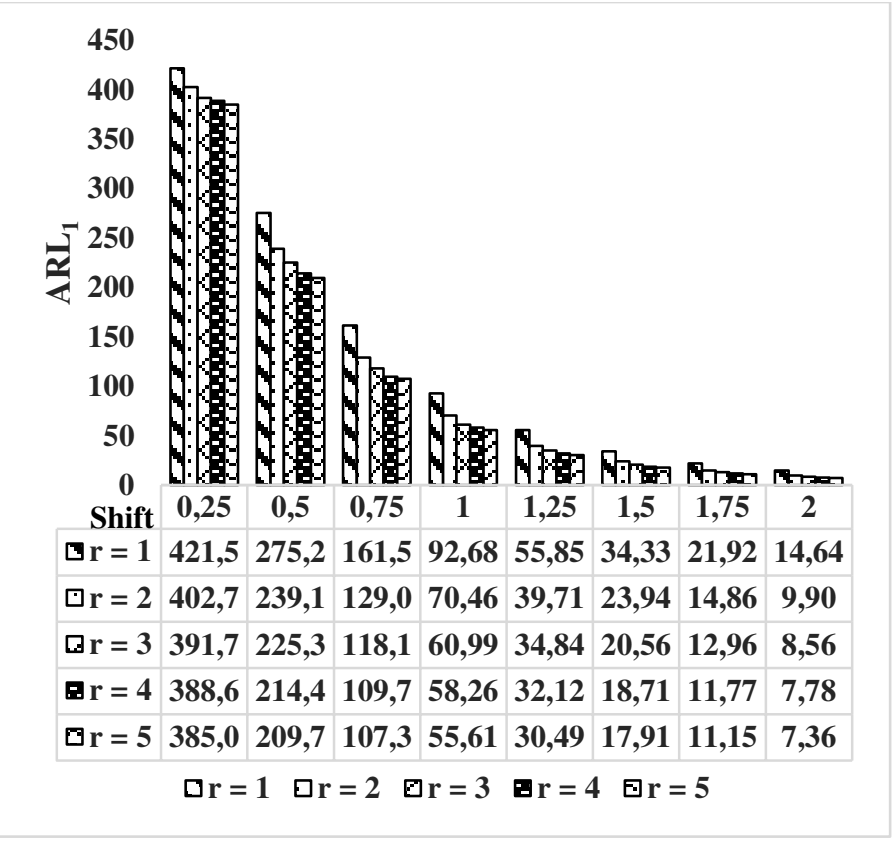

(a) $A R L_{1}$

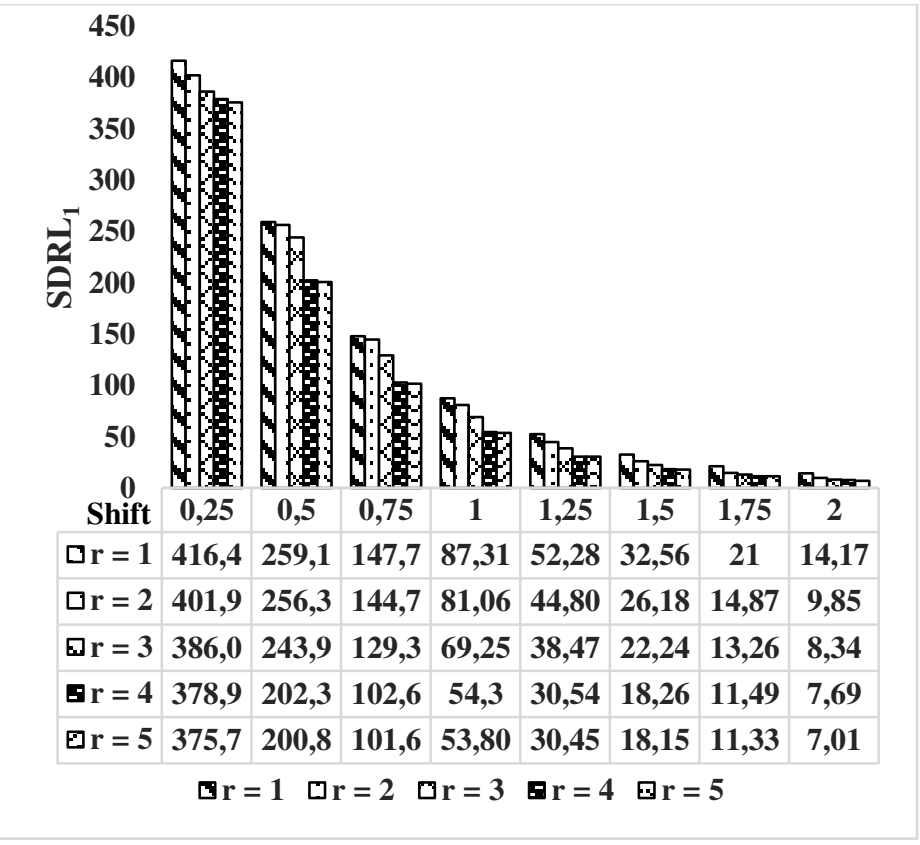

(b) $S D R L_{1}$

Figure 3: $A R L_{1}$ and $S D R L_{1}$ profiles for the HWMA $\bar{X}^{*}$ scheme when $m=100, \lambda=0.9, \gamma=0.9$ and $r \in\{1,2,3,4,5\}$ 




(a) $\lambda=0.1$

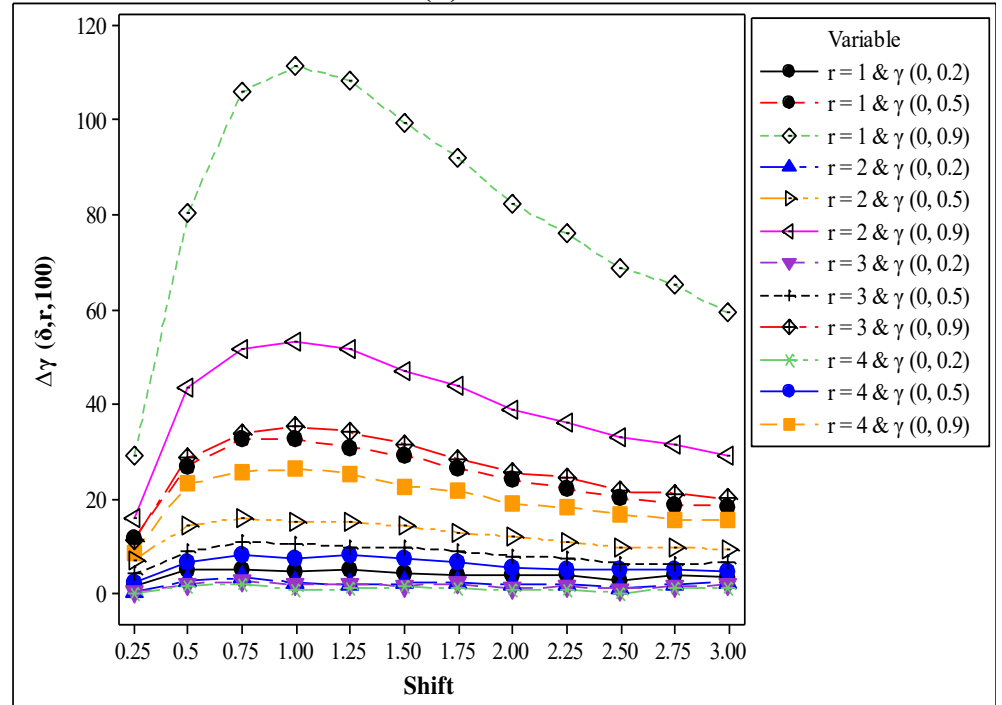

(b) $\lambda=0.5$

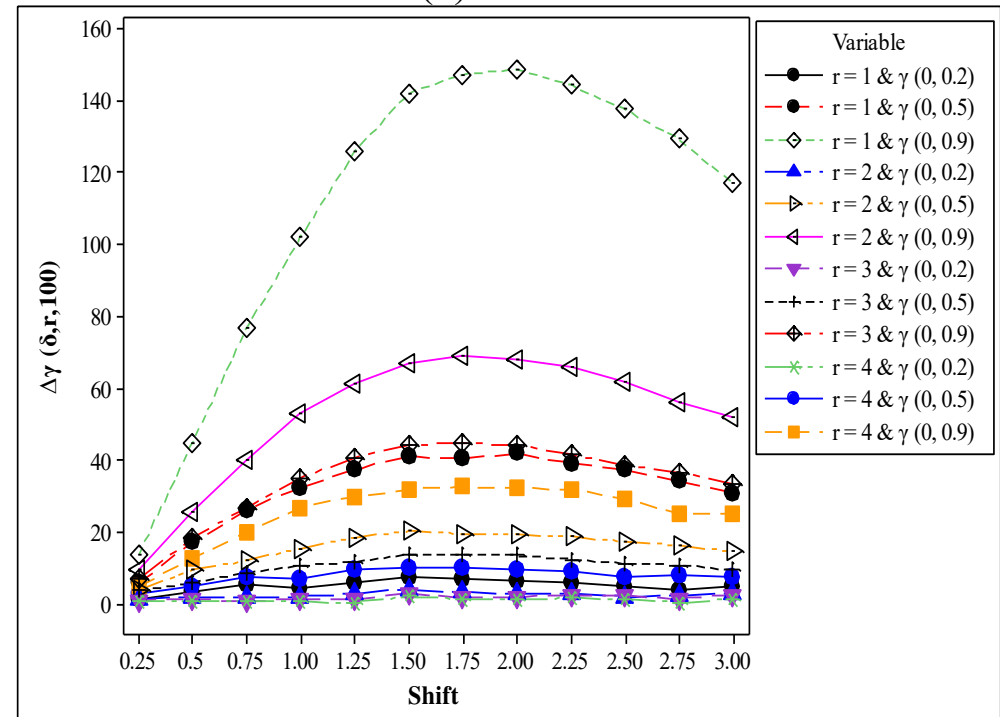

(c) $\lambda=0.9$

Figure 4: $\Delta_{\gamma}(\delta, r, m)$ values of the HWMA $\bar{X}^{*}$ scheme for different values of $\gamma$ and $\lambda$ when

$$
(m, n)=(100,5)
$$




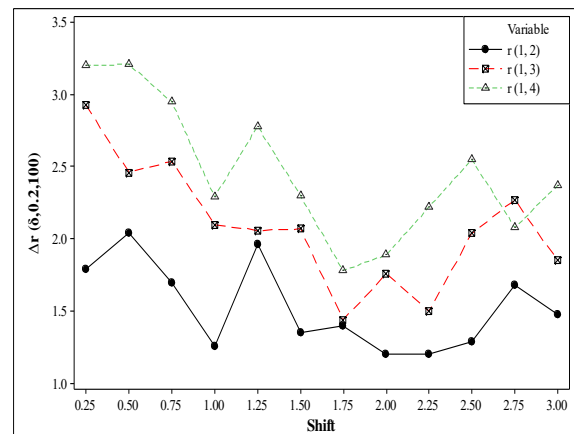

(a) $\gamma=0.2$ and $\lambda=0.1$



(d) $\gamma=0.2$ and $\lambda=0.5$

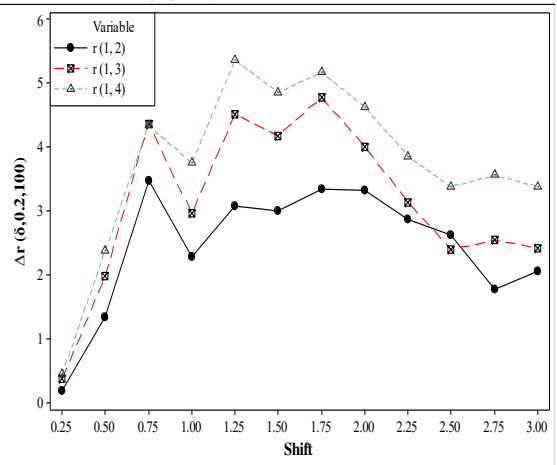

(g) $\gamma=0.2$ and $\lambda=0.9$



(b) $\gamma=0.5$ and $\lambda=0.1$

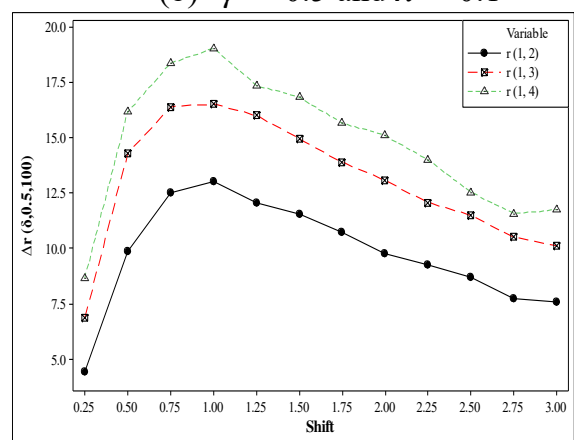

(e) $\gamma=0.5$ and $\lambda=0.5$

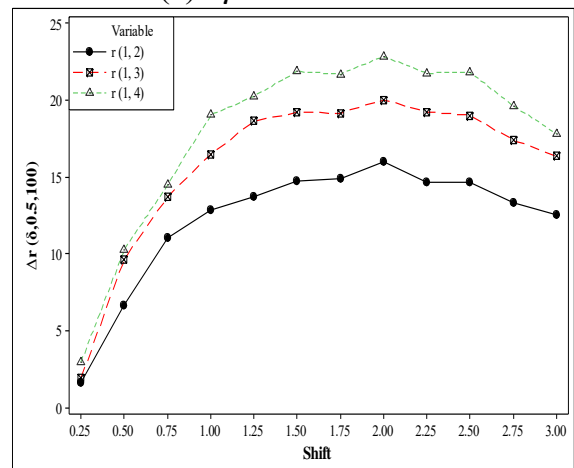

(h) $\gamma=0.5$ and $\lambda=0.9$

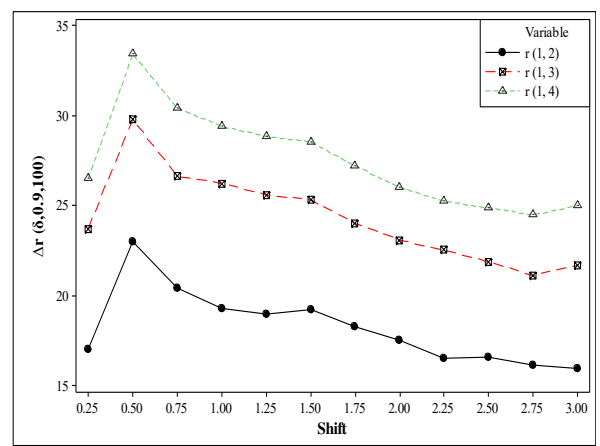

(c) $\gamma=0.9$ and $\lambda=0.1$

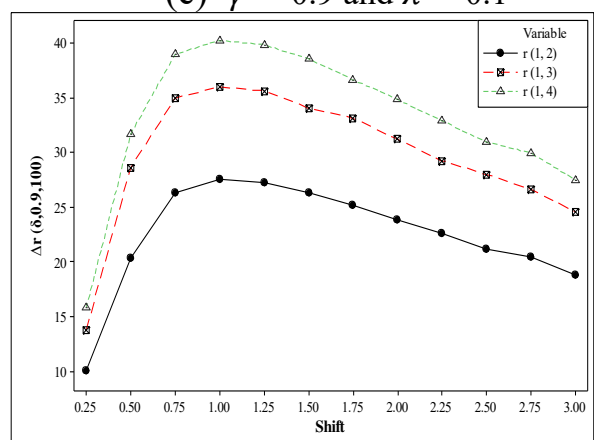

(f) $\gamma=0.9$ and $\lambda=0.5$

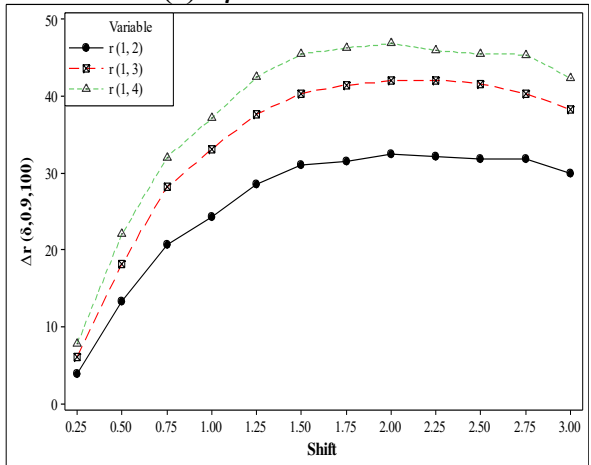

(i) $\gamma=0.9$ and $\lambda=0.9$

Figure 5: $\Delta_{r}(\delta, \gamma, m)$ values of the HWMA $\bar{X}^{*}$ scheme for different values of $\gamma$ and $\lambda=0.1$ when $(m, n)=(100,5)$

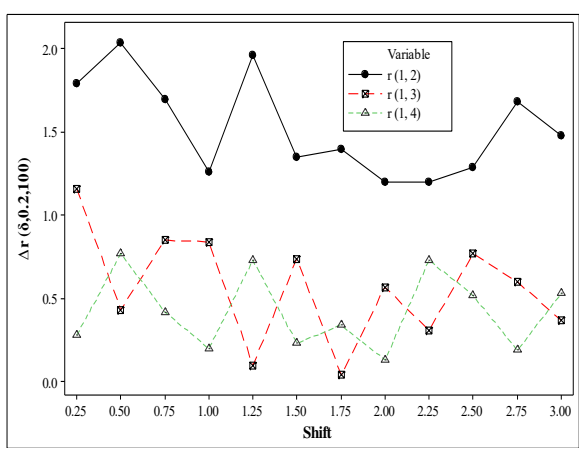

(a) $\gamma=0.2$

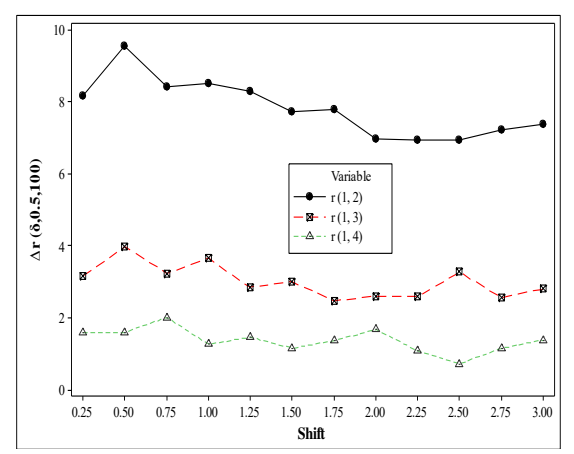

(b) $\gamma=0.5$

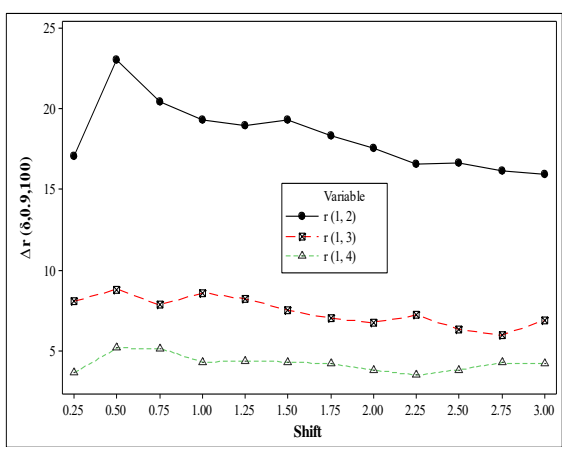

(c) $\gamma=0.9$

Figure 6: Case $\mathrm{U}$ marginal $\Delta_{r}(\delta, \gamma, 100)$ of the HWMA $\bar{X}^{*}$ scheme when $\lambda=0.1$ and $\gamma \in\{0.2,0.5,0.9\}$ 


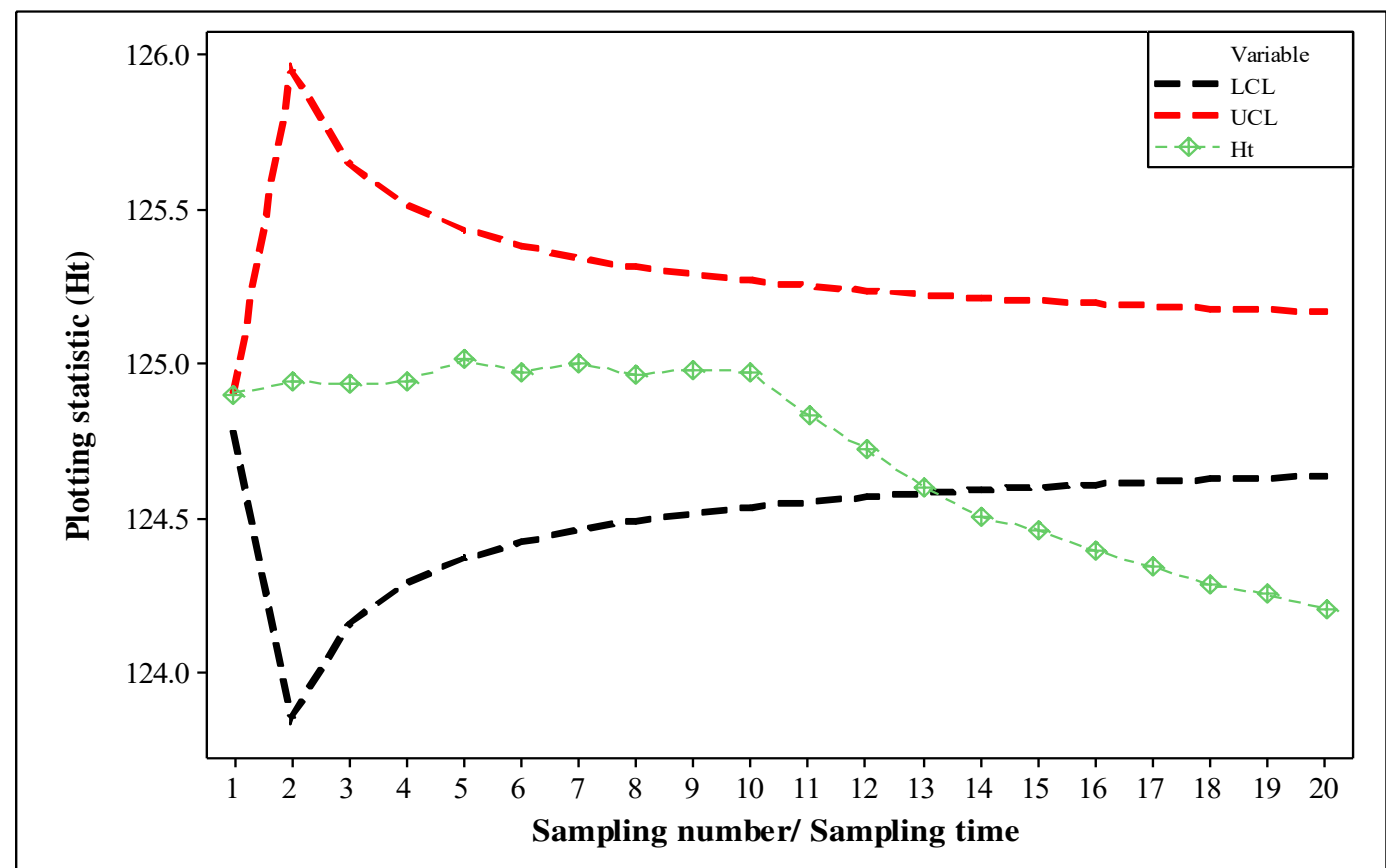

Figure 7: Illustrative example of the HWMA $\bar{X}^{*}$ scheme using the yogurt cup filling data

Figure 1: $A R L_{1}$ profiles for the HWMA $\bar{X}^{*}$ scheme when $\lambda=0.1, \quad \gamma=0.5$ and $m \in\{20,40,100, \infty\}$

Figure 2: $A R L_{1}$ profiles for the HWMA $\bar{X}^{*}$ scheme when $m=100, \gamma=0.5$ and $\lambda \in\{0.1,0.5,0.9\}$

Figure 3: $A R L_{1}$ and $S D R L_{1}$ profiles for the HWMA $\bar{X}^{*}$ scheme when $m=100, \lambda=0.9, \gamma=0.9$ and $r \in\{1,2,3,4,5\}$

Figure 4: $\Delta_{\gamma}(\delta, r, m)$ values of the HWMA $\bar{X}^{*}$ scheme for different values of $\gamma$ and $\lambda$ when $(m, n)=(100,5)$

Figure 5: $\Delta_{r}(\delta, \gamma, m)$ values of the HWMA $\bar{X}^{*}$ scheme for different values of $\gamma$ and $\lambda=0.1$ when $(m, n)=(100,5)$

Figure 6: Case U marginal $\Delta_{r}(\delta, \gamma, 100)$ of the HWMA $\bar{X}^{*}$ scheme when $\lambda=0.1$ and $\gamma \in\{0.2,0.5,0.9\}$

Figure 7: Illustrative example of the HWMA $\bar{X}^{*}$ scheme using the yogurt cup filling data 